\title{
Mitigation of railway induced ground vibration by heavy masses next to the

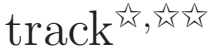

\author{
A. Dijckmans ${ }^{1}$, P. Coulier ${ }^{1}$, J. Jiang ${ }^{2}$, M.G.R. Toward ${ }^{2}$, D.J. Thompson ${ }^{2}$, G. Degrande ${ }^{1}$, G. Lombaert ${ }^{1}$ \\ 1 KU Leuven, Department of Civil Engineering, Kasteelpark Arenberg 40, B-3001 Leuven, Belgium \\ 2 Institute of Sound and Vibration Research, University of Southampton, Southampton SO17 1BJ, UK
}

\begin{abstract}
The effectiveness of heavy masses next to the track as a measure for the reduction of railway induced ground vibration is investigated by means of numerical simulations. It is assumed that the heavy masses are placed in a continuous row along the track forming a wall. Such a continuous wall could be built as a gabion wall and also used as a noise barrier. Since the performance of mitigation measures on the transmission path strongly depends on local ground conditions, a parametric study is performed for a range of possible designs in a set of different ground types. A two-and-a-half dimensional coupled finite element - boundary element methodology is used, assuming that the geometry of the problem is uniform in the direction along the track. It is found that the heavy masses start to be effective above the mass-spring resonance frequency which is determined by the dynamic stiffness of the soil and the mass of the wall. At frequencies above this resonance frequency, masses at the soil's surface hinder the propagation of surface waves. It is therefore beneficial to make the footprint of the masses as large and stiff as possible. For homogeneous soil conditions, the effectiveness is nearly independent of the distance behind the wall. In the case of a layered soil with a soft top layer, the vibration reduction strongly decreases with increasing distance from the wall.
\end{abstract}

Keywords: ground-borne vibration, heavy masses, gabion wall, 2.5D modelling, coupled finite element boundary element models.

\section{Introduction}

Railway induced ground vibration can be a source of annoyance for lineside residents. Vibration in buildings $(1-80 \mathrm{~Hz})$ may cause malfunctioning of sensitive equipment and lead to discomfort of inhabitants. The vibrating walls and floors also radiate noise in the low frequency range $(16-250 \mathrm{~Hz})$. In case of

\footnotetext{
${ }_{4}$ Postprint submitted to Soil Dynamics and Earthquake Engineering

触 Published version: A. Dijckmans, P. Coulier, J. Jiang, M.G.R. Toward, D.J. Thompson, G. Degrande and G. Lombaert. Mitigation of railway induced ground vibration by heavy masses next to the track. Soil Dynamics and Earthquake Engineering, 75:158-170, 2015. http://dx.doi.org/10.1016/j.soildyn.2015.04.003

*Corresponding author. Phone: + 32163777 96. Fax: + 3216321988.

Email address: arne.dijckmans@bwk.kuleuven.be (A. Dijckmans $\left.{ }^{1 *}\right)$
} 
excessive vibration levels, mitigation measures can be taken at the source, on the transmission path, or at the building where vibration problems occur $[1,2]$. The most effective way is to tackle the problem at the source [3]. Mitigation measures at the source for railway induced ground-borne noise and vibration include soft railpads [4], under-sleeper pads [5], ballast mats [6, 7] and floating slab tracks [8] and are frequently used for new railway infrastructure. Vibration reduction measures at the receiver side, such as base isolation [9], are only effective for the structure to which the mitigation measure is applied.

Renewed attention has recently been paid to vibration reduction technologies in the transmission path, but installed close to the track so that they can still be regarded as part of the railway infrastructure [10]. These measures include include open trenches [11], soft and stiff buried wall barriers [12, 13, 14, 15], subgrade stiffening $[16,17]$ and wave impeding blocks $[18,19]$. Interventions on the propagation path between source and receiver have the advantage that no modifications of the track are required. This paper focuses on the possible application of heavy masses next to the track as a feasible vibration mitigation measure on the transmission path.

Jones [1] investigated the effect of concrete masses placed in various configurations along the track. Krylov [20] studied the effect of individual masses such as concrete or stone blocks placed on the ground surface along the track. The reduction in transmitted vibration obtained by blocks at the surface is attributed to the scattering of the incident surface waves into surface and body waves. Similar studies of the scattering of waves by irregularities at the surface have been performed in the fields of solid state physics [21] and earthquake engineering $[22,23,24]$. The scattering turns out to depend on the spatial distribution and the number of irregularities per unit area [21]. In the case of soft soils, seismic wave fields are scattered when the excitation frequencies are close to the resonance frequencies of buildings on the ground stiffness [22]. Similarly, heavy masses next to the track are expected to be especially effective in reducing vibrations near the natural frequency of the mass coupled to the soil $[1,20]$. Two-dimensional (2D) calculations indicate insertion loss values up to $10 \mathrm{~dB}$ in a frequency range from about $20 \%$ below to about $20 \%$ above the natural frequency [20]. Tests with $600 \mathrm{~kg}$ concrete masses failed to give conclusive results [1].

More recently, Mhanna et al. [25] and Masoumi et al. [26] investigated the vibration mitigation effect of heavy masses by means of numerical simulations and experiments. Mhanna et al. [25] used a 3D time domain finite element (FE) model and compared simulations with test results for steel tanks filled with water. The observed reduction in vibrations was attributed to reflection of incident waves by the stiff irregularities, restriction of ground surface movements by the heavy masses and destructive interference between direct and secondary scattered waves. Masoumi et al. [26] investigated the effectiveness of a row of concrete blocks with a two-and-a-half-dimensional (2.5D) coupled finite element - boundary element (FE-BE) model. The model was validated with small scale tests performed in a test bench and full scale tests next to a railway line. Simulations showed an increased reduction for wider and heavier blocks. Including a resilient layer under the concrete blocks significantly reduced the effectiveness. 
The reduction in transmitted vibration by heavy masses next to the track has been attributed to different phenomena. It is the aim of this paper to identify relevant physical phenomena that contribute to the vibration reduction and thus improve the knowledge necessary for the design of heavy masses as a vibration mitigation measure.

In this study, a continuous row of masses along the track is considered. Although the results of the theoretical analysis are generally applicable, gabion walls consisting of free standing stackable wire baskets filled with stones are considered in this paper. Gabion walls have been installed as noise barriers next to railway lines (figure 1). In this case, an acoustic nucleus is integrated within the wall to fulfill the acoustic requirements on sound transmission. The noise barriers consist of gabions with a width of $1 \mathrm{~m}$ and a height of $0.5 \mathrm{~m}$ or $1 \mathrm{~m}$, possibly stacked next to or on top of each other. The length of the gabions forming the wall can vary between $1 \mathrm{~m}$ and $5 \mathrm{~m}$. If the gabions would also lead to a significant reduction of ground-borne vibration, such a wall could be designed as a combined barrier for airborne noise [27] and ground-borne vibration. Because the stiffness of the gabions is of the same order of magnitude as the stiffness of typical soils, the gabion walls primarily act as an additional mass on the soil's surface. The case of a continuous concrete wall next to the track is included in the present study to investigate the performance of a stiff barrier.

(a)

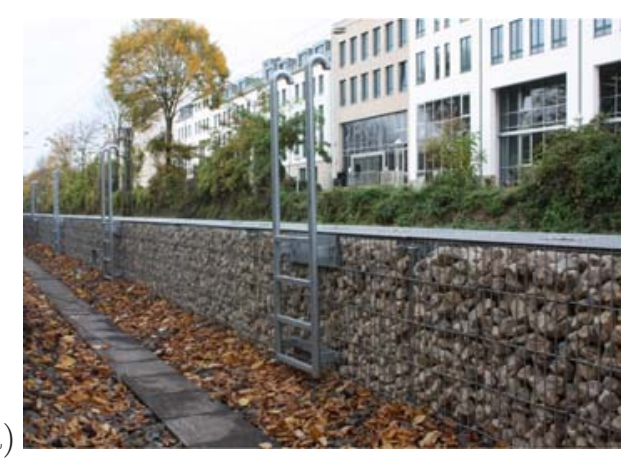

(b)

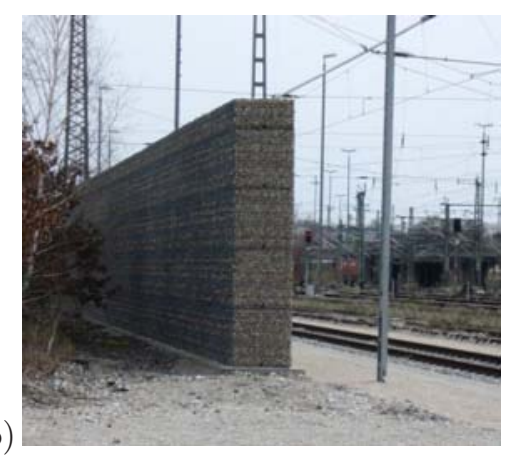

Figure 1: Gabion walls installed as noise barriers next to railway tracks in (a) Bonn-Südstadt and (b) München Laim. Photos courtesy of (a) Deutsche Bahn AG, Gerd LeDosquet and (b) Deutsche Bahn AG, Hans-Jörg Terno.

The outline of this paper is as follows. Section 2 describes the $2.5 \mathrm{D}$ model used for the analysis of the vibration reduction of heavy masses next to the track. Results for a benchmark reference case are presented in section 3. To explain the observations made in the benchmark study, different idealized models with an increasing degree of complexity are set up. In section 4, the underlying physical mechanisms are discussed in detail by comparing results from different simplified models. In section 5, a comprehensive parametric study is performed to study the influence of the size of the wall and the soil characteristics. Concluding remarks are given in section 6 . 


\section{Methodology}

Figure 2 gives a schematic view of the problem considered in the parametric study. A continuous wall with height $h$ and width $w$ is placed on the soil's surface at a distance $d$ from the centre of the track. The origin of the Cartesian frame of reference is placed at the soil's surface at the centre of the track. The $x$-axis is in the direction perpendicular to the track, the $y$-axis is parallel to the track and the $z$-axis is vertical.

The free field response due to a train passage can be calculated from the track-soil transfer function (impulse response function) $H_{\mathrm{ts}}\left(\mathbf{x}, \mathbf{x}^{\prime}, t\right)$ that relates the response at a point $\mathbf{x}^{\prime}$ to the load at a point $\mathbf{x}$ on the track as follows [28]:

$$
u\left(\mathbf{x}^{\prime}, t\right)=\sum_{k=1}^{n_{\mathrm{a}}} \int_{-\infty}^{t} H_{\mathrm{ts}}\left(\mathbf{x}_{k}(\tau), \mathbf{x}^{\prime}, t-\tau\right) g_{k}(\tau) \mathrm{d} \tau
$$

where $n_{\mathrm{a}}$ is the number of axles, $\mathbf{x}_{k}(t)$ is the position of the $k$-th axle $\left(k=1, \ldots, n_{\mathrm{a}}\right)$ and $g_{k}(t)$ is the time history of the load of the $k$-th axle. The transfer function $H_{\mathrm{ts}}\left(\mathbf{x}, \mathbf{x}^{\prime}, t\right)$ between the track and the free field determines how the loads applied to the track are transferred to the soil.

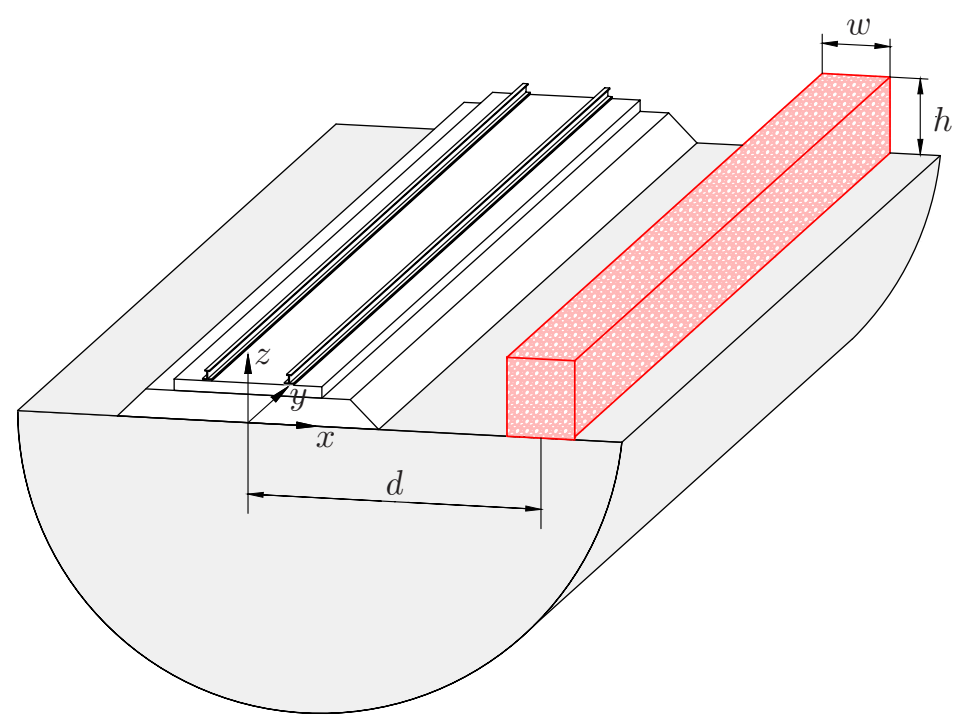

Figure 2: Geometry of the 2.5D model for heavy masses next to a railway track.

The axle loads can be decomposed into static and dynamic load components [29]. At frequencies above a few Hertz, the response in the free field sufficiently far from the track is dominated by the dynamic load if the train speed is small compared to the Rayleigh wave velocity $C_{\mathrm{R}}$ of the soil. This dynamic load is determined by train-track interaction resulting from several excitation mechanisms such as wheel and track unevenness and parametric excitation caused by the spatial variation of support stiffness. Often only the dynamic axle loads originating from the track unevenness are taken into account. The dynamic axle loads 
are calculated based on a compliance formulation in a moving frame of reference, which requires the vehicle and track compliance [28].

In this paper, the free field response and insertion loss for the passage of a train are calculated in a simplified way to reduce the calculation time. Previous studies have shown that the stationary part of the free field response due to the passage of a train can be well approximated by assuming the dynamic axle loads to be applied at fixed positions, i.e. $\mathbf{x}_{k}(t) \approx \mathbf{x}_{k 0}[30]$. Assuming in addition that the axle loads are incoherent, equation (1) can be simplified and written in the frequency domain as:

$$
\left|\hat{u}\left(\mathbf{x}^{\prime}, \omega\right)\right|^{2}=\sum_{k=1}^{n_{\mathrm{a}}}\left|\hat{H}_{\mathrm{ts}}\left(\mathbf{x}_{k 0}, \mathbf{x}^{\prime}, \omega\right) \hat{g}_{k}(\omega)\right|^{2}
$$

where $\omega$ is the radial frequency and a hat above a variable denotes its representation in the frequency domain. The train load considered in this paper is thus represented by a sequence of fixed, incoherent point sources. It is furthermore assumed that the forces applied by different axles have the same amplitude, i.e. $\hat{g}_{k}(\omega)=\hat{g}_{0}(\omega)$.

The transfer functions $\hat{H}_{\mathrm{ts}}\left(\mathbf{x}_{k 0}, \mathbf{x}^{\prime}, \omega\right)$ are determined by track-soil-wall interaction. Because the distance between the railway track and the wall is small, through-soil coupling between the track and the wall cannot be disregarded. In this paper, the geometry of the track-soil-wall system is assumed to be uniform along the track. The soil is modelled as a horizontally layered halfspace. An equivalent continuous model [28] is employed for the track which has a periodic layout due to the discrete support of the sleepers.

The assumption of a longitudinally invariant geometry enables the use of a computationally efficient $2.5 \mathrm{D}$ approach, where a Fourier transformation of the coordinate $y$ along the track to the wavenumber $k_{y}$ leads to an efficient solution in the frequency-wavenumber domain:

$$
\tilde{u}\left(x, k_{y}, z, \omega\right)=\int_{-\infty}^{+\infty} \hat{u}(x, y, z, \omega) \exp \left(\mathrm{i} k_{y} y\right) \mathrm{d} y
$$

A tilde above a variable denotes its representation in the frequency-wavenumber domain. A track-soilwall interaction problem with $2 \mathrm{D}$ geometry is solved for each frequency $\omega$ and wavenumber $k_{y}$ to compute $\tilde{u}\left(x, k_{y}, z, \omega\right)$ and the $3 \mathrm{D}$ solution $\hat{u}(x, y, z, \omega)$ is obtained by an inverse Fourier transformation with respect to the wavenumber $k_{y}$ :

$$
\hat{u}(x, y, z, \omega)=\frac{1}{2 \pi} \int_{-\infty}^{+\infty} \tilde{u}\left(x, k_{y}, z, \omega\right) \exp \left(-\mathrm{i} k_{y} y\right) \mathrm{d} k_{y} .
$$

The track-soil-wall interaction problem is solved by means of a coupled FE-BE methodology [31]. The track and heavy masses are modelled by means of finite elements, while boundary elements on the soilstructure interfaces are used to model the layered soil domain. A weak variational formulation of the 
equilibrium of the track (structure $j=1$ ) and the wall (structure $j=2$ ) results in the following set of coupled FE-BE equations [31]:

$$
\left[\tilde{\mathbf{K}}_{j}\left(k_{y}, \omega\right)-\omega^{2} \mathbf{M}_{j}\right] \underline{\tilde{\underline{u}}}_{j}\left(k_{y}, \omega\right)+\sum_{k=1}^{2} \tilde{\mathbf{K}}_{j k}^{\mathrm{s}}\left(k_{y}, \omega\right) \underline{\underline{\underline{u}}}_{k}\left(k_{y}, \omega\right)=\tilde{\mathbf{f}}_{j}\left(k_{y}, \omega\right) \quad \text { for } \quad j=1,2 .
$$

$\underline{\tilde{\mathbf{u}}}_{j}\left(k_{y}, \omega\right)$ collects the nodal degrees of freedom of structure $j$, while $\tilde{\mathbf{K}}_{j}\left(k_{y}, \omega\right)$ and $\mathbf{M}_{j}$ are the finite element stiffness and mass matrix of this structure. The stiffness matrix $\tilde{\mathbf{K}}_{j}\left(k_{y}, \omega\right)$ can be elaborated as follows [31]:

$$
\tilde{\mathbf{K}}_{j}\left(k_{y}, \omega\right)=\tilde{\mathbf{K}}_{j}^{0}-\mathrm{i} k_{y} \tilde{\mathbf{K}}_{j}^{1}-k_{y}^{2} \tilde{\mathbf{K}}_{j}^{2} \quad \text { for } \quad j=1,2
$$

where $\tilde{\mathbf{K}}_{j}^{0}$ corresponds to a combination of the classical two-dimensional in-plane and out-of-plane stiffness matrix. The stiffness matrices $\tilde{\mathbf{K}}_{j}^{1}$ and $\tilde{\mathbf{K}}_{j}^{2}$ account for $3 \mathrm{D}$ wave propagation in the structure. $\tilde{\mathbf{K}}_{j k}^{\mathrm{s}}\left(k_{y}, \omega\right)$ is the dynamic soil stiffness matrix and is computed by means of the BE method. $\tilde{\mathbf{K}}_{12}^{\mathrm{s}}\left(k_{y}, \omega\right)$ and $\tilde{\mathbf{K}}_{21}^{\mathrm{s}}\left(k_{y}, \omega\right)$ represent the through-soil coupling between the track and the wall. The force vector $\tilde{\mathbf{f}}_{j}\left(k_{y}, \omega\right)$ results from the external forces on structure $j$, in this case the dynamic axle load on the track.

\section{Benchmark reference case}

The case of a gabion wall with a height $h=2 \mathrm{~m}$ and a width $w=1 \mathrm{~m}$ is taken as reference. The wall is placed at $d=4 \mathrm{~m}$ from the track centre line, which is the typical distance of noise barriers. Calculations are performed with the 2.5D coupled FE-BE software BEMFUN [31] and WANDS [32]. The track is disregarded to eliminate possible discrepancies caused by small differences in the track models of BEMFUN and WANDS. The soil is assumed to be homogeneous. A halfspace with layer thickness $h$ and dynamic soil characteristics (shear wave velocity $C_{\mathrm{s}}$, dilatational wave velocity $C_{\mathrm{p}}$, density $\rho$, material damping ratios $\beta_{\mathrm{s}}$ and $\beta_{\mathrm{p}}$ in both deviatoric and volumetric deformation) given in table 1 is considered. These soil properties correspond to a saturated sandy soil as present at a site in Horstwalde (Germany), which is described in more detail in section 5.2. The density of the fill material of the gabions is approximately $1700 \mathrm{~kg} / \mathrm{m}^{3}$. The stiffness and damping properties of the gabion wall are estimated from typical properties of track ballast: a shear wave velocity $C_{\mathrm{s}}=300 \mathrm{~m} / \mathrm{s}$, a Poisson's ratio $\nu=0.20$ and material damping ratios $\beta_{\mathrm{s}}=\beta_{\mathrm{p}}=0.02$. The wall is modelled as an elastic continuum taking into account the flexibility of the cross section and stiffness in the longitudinal direction. It is therefore assumed that the gabion baskets are interconnected so that wave propagation in the wall along the track is possible.

In the BEMFUN model, the gabion wall is modelled using a 10 by 10 mesh of eight-node quadrilateral 2.5D finite elements (figure 3a). The finite element model of the gabion wall is coupled to a conforming boundary element mesh using 10 3-node elements for the layered soil. This mesh ensures that there are at 


\begin{tabular}{ccccccc}
\hline Layer & $h$ & $C_{\mathrm{s}}$ & $C_{\mathrm{p}}$ & $\beta_{\mathrm{s}}$ & $\beta_{\mathrm{p}}$ & $\rho$ \\
& {$[\mathrm{m}]$} & {$[\mathrm{m} / \mathrm{s}]$} & {$[\mathrm{m} / \mathrm{s}]$} & {$[-]$} & {$[-]$} & {$\left[\mathrm{kg} / \mathrm{m}^{3}\right]$} \\
\hline 1 & $\infty$ & 250 & 1470 & 0.025 & 0.025 & 1945 \\
\hline
\end{tabular}

Table 1: Dynamic soil characteristics for the Horstwalde site.

least 10 elements per wave length up to $100 \mathrm{~Hz}$. Green's functions for a halfspace are used as fundamental solutions in the $\mathrm{BE}$ formulation $[33,34]$. The boundary element mesh can therefore be limited to the interface between the mass and the soil. Calculations are made for frequencies between 1 and $100 \mathrm{~Hz}$ with a frequency bin $\Delta f=1 \mathrm{~Hz}$. A linear wavenumber sampling from $\bar{k}_{y}=0$ to $\bar{k}_{y}=1.2$ with $\Delta \bar{k}_{y}=0.01$, completed with a logarithmic sampling of 50 samples up to $\bar{k}_{y}=100$, is used in terms of the dimensionless wavenumber $\bar{k}_{y}=k_{y} C_{\mathrm{s}} / \omega$.

In the WANDS model, the gabion wall is modelled using a 4 by 8 mesh of eight-node 2.5D finite elements and the ground is modelled using 3-node boundary elements with a maximum element size equal to $0.38 \mathrm{~m}$ (figure 3b). Using these elements ensures that there are at least 6 elements per wave length up to $100 \mathrm{~Hz}$. Fundamental solutions of a homogeneous full space are used for the boundary element formulation. The ground surface is meshed from $x=-10 \mathrm{~m}$ to $x=68 \mathrm{~m}$. A special edge element [35] is used to avoid reflections at the end of the ground mesh. Calculations are made for 3 frequencies in each one-third octave band covering the bands 1.25 to $100 \mathrm{~Hz}$ at wavenumbers $k_{y}$ from -8 to $8 \mathrm{rad} / \mathrm{m}$ with $\Delta k_{y}=16 / 1024 \mathrm{rad} / \mathrm{m}$.

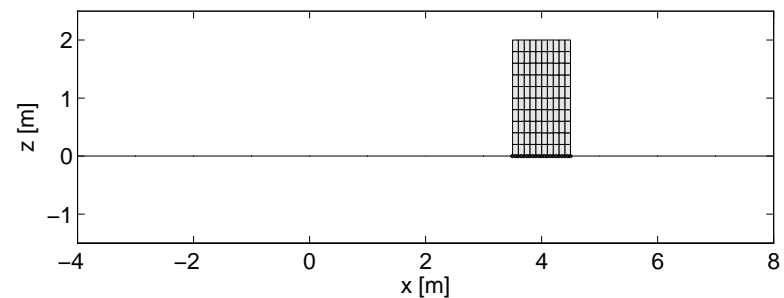

(a)

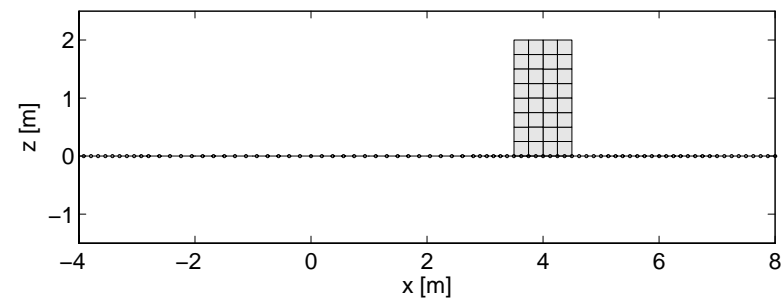

(b)

Figure 3: Finite element and boundary element discretization for the benchmark reference case in (a) the BEMFUN model and (b) the WANDS model.

Figure 4 shows the transfer mobilities between a vertical point load applied at the soil's surface at $(x=0 \mathrm{~m}, y=0 \mathrm{~m})$ and the vertical velocity at $y=0 \mathrm{~m}$ at several distances from the source for the cases without and with gabion wall. The corresponding insertion loss values are shown in figure 5. The gabion wall does not affect the transmission of vibrations at frequencies below $30 \mathrm{~Hz}$, apart from a small peak in insertion loss at $12 \mathrm{~Hz}$ related to a rocking mode of the gabion wall (section 4.2). Around $60 \mathrm{~Hz}$, a peak value of $8 \mathrm{~dB}$ is obtained for the insertion loss. Above this frequency, the insertion loss starts to decrease again. A very good agreement is observed between results obtained by both models.

At first sight, these results show the resonant behaviour of masses next to the track as reported previously in literature $[1,20]$. Modelling the heavy mass as a simple point mass, a maximum reduction is obtained 


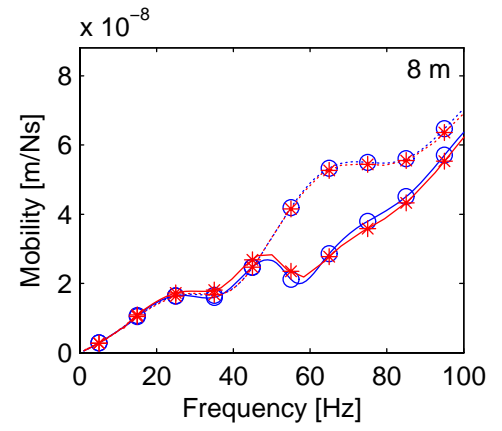

(a)

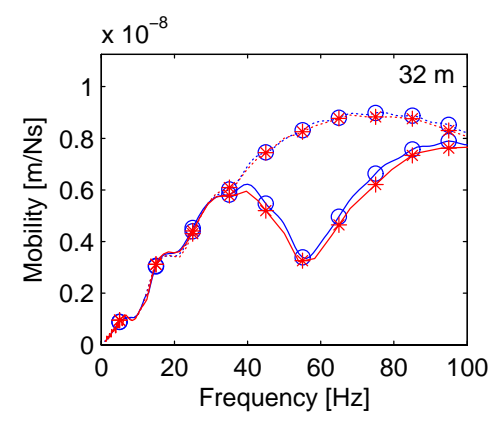

(d)

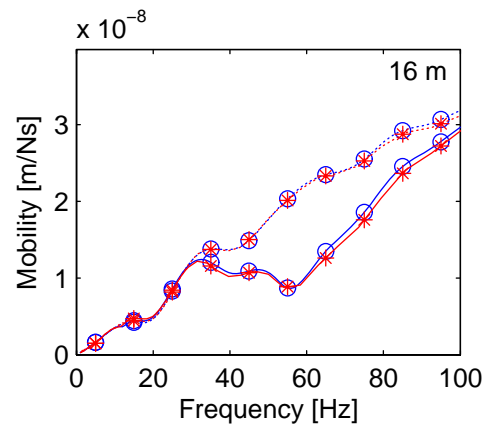

(b)

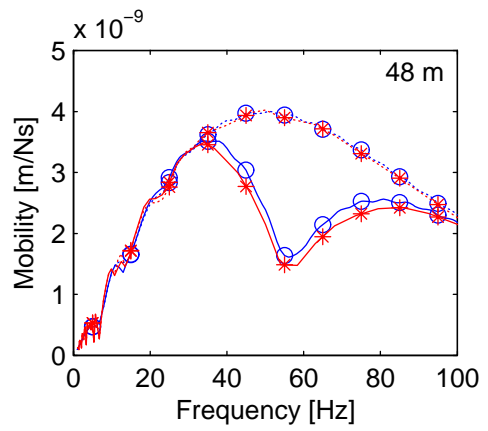

(e)

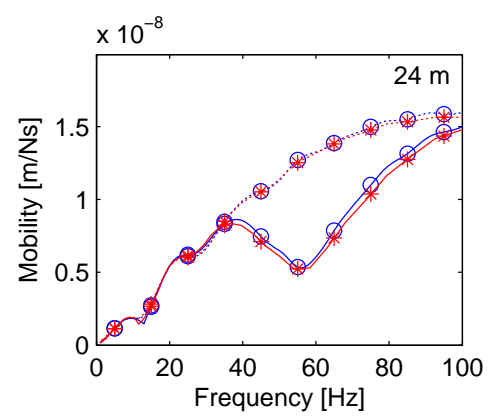

(c)

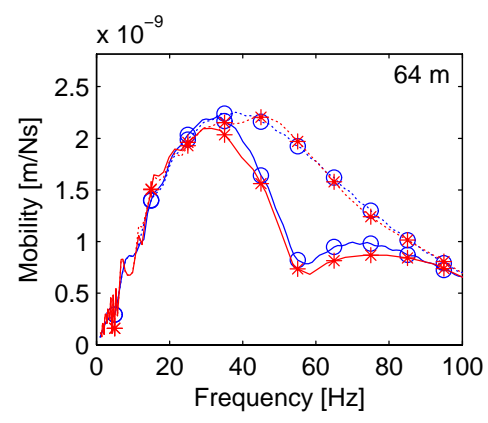

(f)

Figure 4: Transfer mobility without (dotted lines) and with (solid lines) a gabion wall (width $1 \mathrm{~m}$, height $2 \mathrm{~m}$ ) for a point load at the Horstwalde site. Results at the soil's surface at $y=0 \mathrm{~m}$ and (a) $x=8 \mathrm{~m}$, (b) $x=16 \mathrm{~m}$, (c) $x=24 \mathrm{~m}$, (d) $x=32 \mathrm{~m}$, (e) $x=48 \mathrm{~m}$, and (f) $x=64 \mathrm{~m}$ obtained with BEMFUN (o) and WANDS $(*)$.

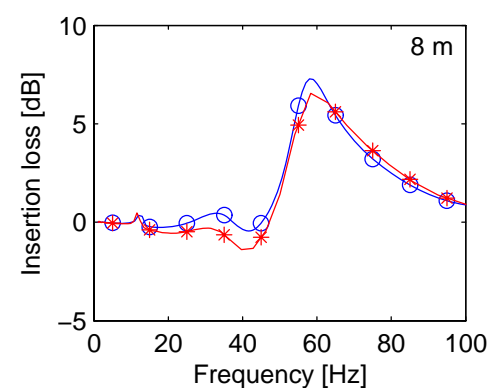

(a)

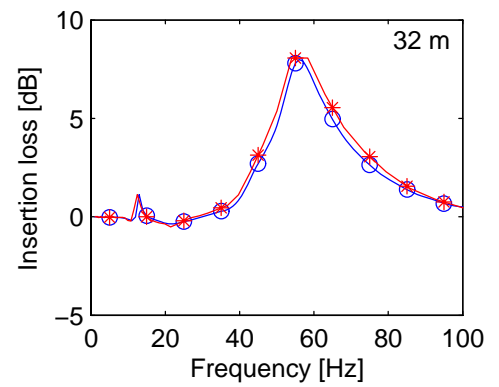

(d)

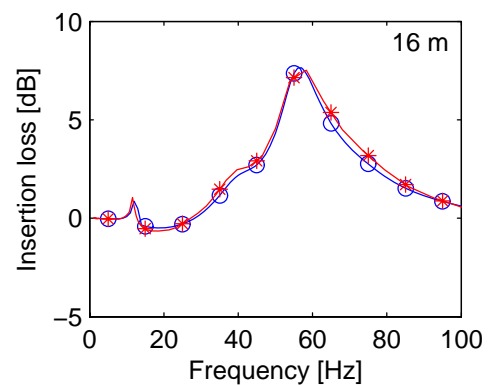

(b)

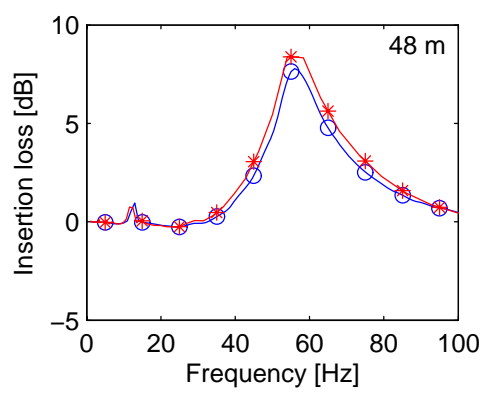

(e)

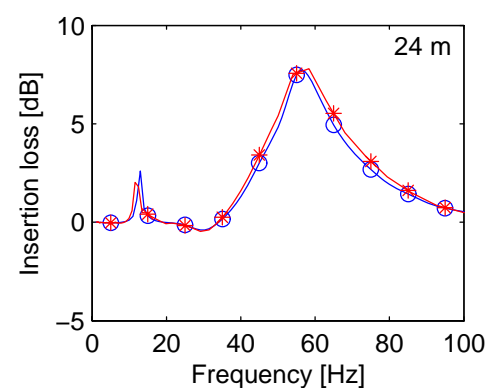

(c)

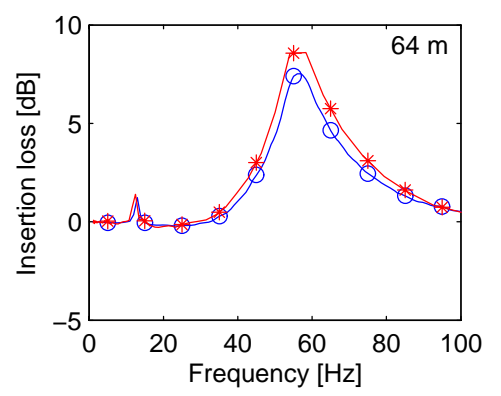

(f)

Figure 5: Vertical insertion loss of a gabion wall (width $1 \mathrm{~m}$, height $2 \mathrm{~m}$ ) for a point load at the Horstwalde site. Results at the soil's surface at $y=0 \mathrm{~m}$ and (a) $x=8 \mathrm{~m}$, (b) $x=16 \mathrm{~m}$, (c) $x=24 \mathrm{~m}$, (d) $x=32 \mathrm{~m}$, (e) $x=48 \mathrm{~m}$, and (f) $x=64 \mathrm{~m}$ obtained with BEMFUN (०) and WANDS (*). 
around the mass-spring resonance frequency of the mass coupled to the soil [20]. The frequency at which a maximum insertion loss is obtained in figure 5 does not correspond, however, with the calculated mass-spring resonance frequency of $41 \mathrm{~Hz}$ for the gabion wall (section 4.2). Furthermore, the small peak at $12 \mathrm{~Hz}$ cannot be predicted with a simplified point or line mass model. Apart from the mass, the finite dimensions of the footprint and the stiffness of the masses also play an important role. This is discussed extensively in the following section.

\section{Physical mechanisms}

In order to investigate the physical mechanisms leading to reduced vibration transmission, additional simulations are performed for the reference case of a gabion wall at the Horstwalde site. As in the previous section, the presence of the track is disregarded to facilitate the physical interpretation of results. Different idealized models with an increasing degree of complexity are set up for the heavy masses. This enables physical interpretation of the observations made in the benchmark study. In the simplest case, they are modelled as a line mass. Next, they are modelled as a wall with rigid cross section to discuss the influence of its finite dimensions. Afterwards, the influence of the cross sectional flexibility and longitudinal stiffness is investigated, both for the reference gabion wall and a concrete wall.

For each case, the vertical insertion loss at the soil-mass interface $(x=4 \mathrm{~m}, y=0 \mathrm{~m})$ and at the soil's surface at $(x=8 \mathrm{~m}, y=0 \mathrm{~m})$ is shown for three different vertical excitations: a unit line load, i.e. for $k_{y}=0$ (2D), a unit point load, and a train load. The train load consists of 16 uncorrelated unit point forces applied at the soil's surface at the axle positions of a typical four-car EMU train [36], when the train is centred at $y=0 \mathrm{~m}$. The considered train has a total length of $106.4 \mathrm{~m}$. Each car is supported by two bogies. The car length is $26.6 \mathrm{~m}$ and the bogie centre distance is $19.0 \mathrm{~m}$. The distance between two axles of a bogie is $2.7 \mathrm{~m}$. The results for the point load and the train load are calculated with the 2.5D approach.

\subsection{Line mass model}

First, the heavy masses are modelled as a distributed line mass on the soil with a mass per unit length of $3400 \mathrm{~kg} / \mathrm{m}$. To represent the line mass, a footprint of $0.01 \mathrm{~m}$ is used in the FE-BE model, which is small compared to the Rayleigh wavelength in the frequency range considered. Lateral motion of the line mass is disregarded in the model, only allowing for vertical translation. This model is similar to the 2D line model used by Krylov [20]. The longitudinal stiffness is disregarded by setting the wall stiffness matrices $\tilde{\mathbf{K}}_{2}^{1}$ and $\tilde{\mathbf{K}}_{2}^{2}$ in equation (6) equal to zero. It is thus assumed that individual masses are not interconnected and wave propagation in the wall along the track direction is prevented. The influence of the longitudinal stiffness is studied in section 4.3 .

Figure 6a shows the insertion loss for the line mass model at the soil-mass interface and at a distance of $8 \mathrm{~m}$ for the $2 \mathrm{D}$ calculation. The behaviour of the distributed line mass resembles that of a mass-spring system, 


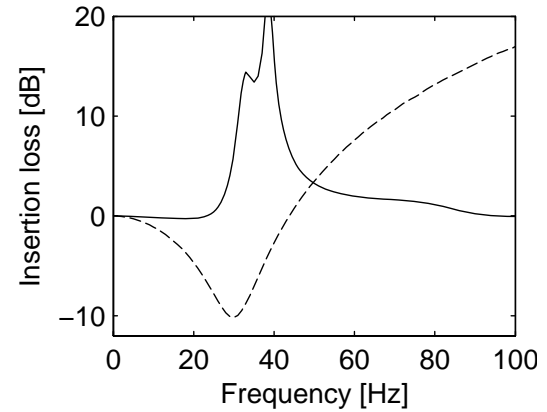

(a)

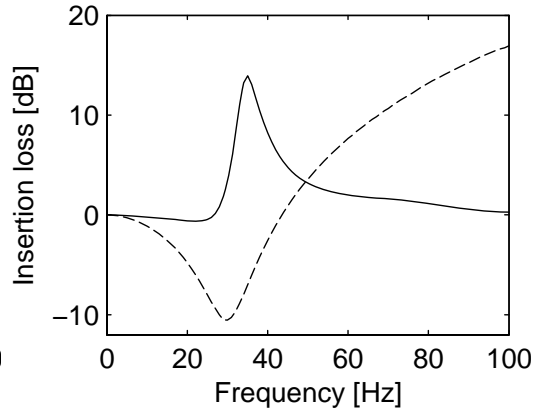

(b)

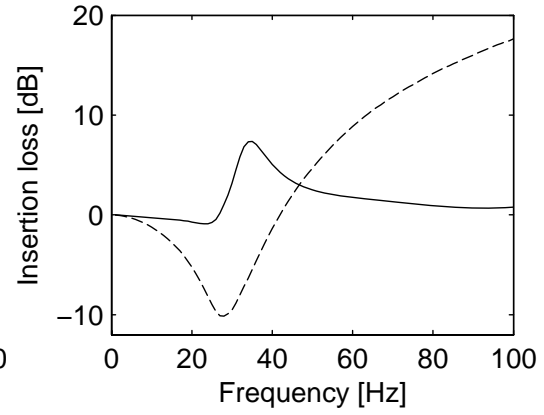

(c)

Figure 6: Vertical insertion loss of a distributed line mass of $3400 \mathrm{~kg} / \mathrm{m}$ without longitudinal stiffness for (a) a line load, (b) a point load, and (c) a train load. Results at $y=0 \mathrm{~m}$ at the soil-mass interface (dashed line) and at the soil's surface at $x=8 \mathrm{~m}$ (solid line).

as found by other researchers $[1,20,26]$. At low frequencies, the mass follows the vertical displacement at the soil's surface and no reduction is seen. Around the mass-spring resonance frequency of $31 \mathrm{~Hz}$, a clear dip is observed in the insertion loss at the soil-mass interface. Above the resonance frequency, the insertion loss rises steeply due to the inertia of the mass. The mass-spring resonance frequency $\omega_{0}$ can be estimated from:

$$
\omega_{0}=\sqrt{\frac{\hat{K}_{z}^{\mathrm{s}}(\omega)}{m}}
$$

where $m$ is the total mass per unit length and $\hat{K}_{z}^{\mathrm{s}}(\omega)$ represents the vertical dynamic stiffness per unit length of the soil under the masses. The stiffness $\hat{K}_{z}^{\mathrm{s}}(\omega)$ can be estimated from the vertical dynamic soil stiffness of a rigid strip foundation. For a line mass of $3400 \mathrm{~kg} / \mathrm{m}$, the predicted resonance frequency for this homogeneous halfspace equals $29.2 \mathrm{~Hz}$, which corresponds well to the observed resonance frequency of $31 \mathrm{~Hz}$ in figure $6 \mathrm{a}$. The imaginary part of $\hat{K}_{z}^{\mathrm{s}}(\omega)$ is approximately $30 \%$ of the real part, which indicates that the radiation damping in the soil is low for the line mass and which explains the pronounced mass-spring resonance dip.

The insertion loss at $8 \mathrm{~m}$ starts to increase at the mass-spring resonance frequency of $31 \mathrm{~Hz}$ (figure 6a). This leads to a peak in the insertion loss curve at $39 \mathrm{~Hz}$. While the insertion loss at the soil-mass interface reaches very high values at higher frequencies, the insertion loss behind the distributed line mass starts to decrease again above $40 \mathrm{~Hz}$. Only a small reduction is predicted above $50 \mathrm{~Hz}$. This can be understood by considering the dynamic behaviour of a simple mass-spring system with an imposed base motion $\hat{u}_{0}(\omega)$. The displacement of the mass $\hat{u}_{m}(\omega)$ is determined by:

$$
\hat{u}_{m}(\omega)=\frac{k}{-m \omega^{2}+k} \hat{u}_{0}(\omega)
$$

where $m$ is the mass and $k$ is the spring stiffness representing the soil. The line mass displacement $\hat{u}_{m}(\omega)$ 
results in a diffracted wave field. The phase difference between $\hat{u}_{m}(\omega)$ and $\hat{u}_{0}(\omega)$ increases from 0 at $0 \mathrm{~Hz}$ to $-\pi / 2$ at the resonance frequency $\omega_{0}$ and further to $-\pi$ at high frequencies. Destructive interference between the incident and diffracted wave field occurs when the phase difference is larger than $\pi / 2$. Therefore, vibration levels behind the line mass are only reduced at and above the resonance frequency. The combination of large mass displacement around $\omega_{0}$ and increasing phase difference above $\omega_{0}$ leads to a peak in insertion loss just above the resonance frequency.

Figure $6 \mathrm{~b}$ shows the insertion loss when a vertical point load is applied at the soil's surface. While the trends for the $2 \mathrm{D}$ and $2.5 \mathrm{D}$ simulations are very similar, the peak of the insertion loss at $8 \mathrm{~m}$ is now found at the slightly lower frequency of $35 \mathrm{~Hz}$ and the maximum insertion loss value is reduced from $21 \mathrm{~dB}$ to $14 \mathrm{~dB}$. The peak insertion loss is further reduced to $7.5 \mathrm{~dB}$ when a train load, consisting of 16 uncorrelated vertical point loads, is considered (figure 6c). This is caused by the large spatial variation of the insertion loss at close distance from the wall (section 5.4). At larger distances, the maximum insertion loss values for a point load and a train load are similar.

\subsection{Model with rigid cross section}

In reality, the heavy masses have finite dimensions and the width of the wall cannot be disregarded in the entire frequency range of interest. The aim of this subsection is to study the influence of the finite dimensions of the footprint. Therefore, a wall with a rigid cross section, only allowing for a global vertical translation and rotation, is considered. The lateral motion and the longitudinal stiffness of the wall are still disregarded. The insertion loss at the soil-mass interface and at the soil's surface at a distance of $8 \mathrm{~m}$ from the source are shown in figure 7 for the three excitation cases.

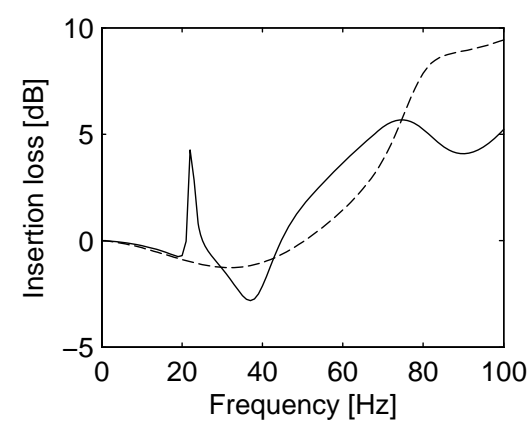

(a)

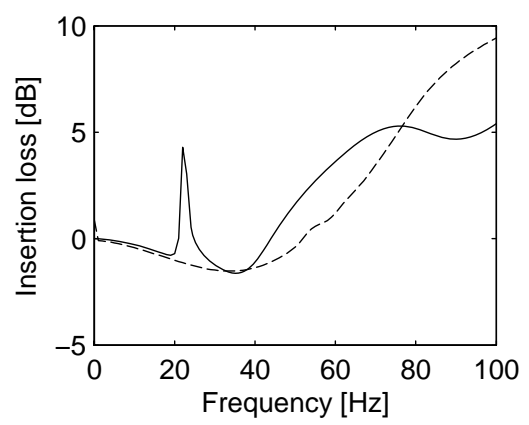

(b)

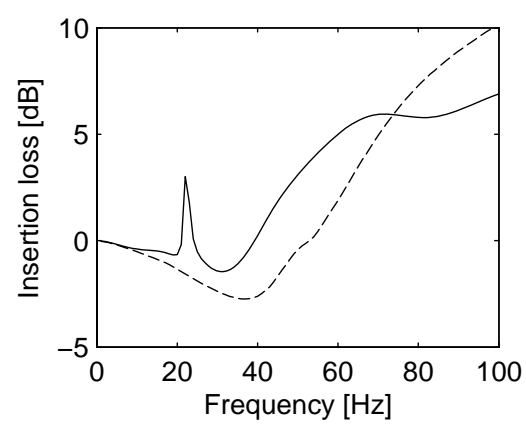

(c)

Figure 7: Vertical insertion loss of a gabion wall (width $1 \mathrm{~m}$, height $2 \mathrm{~m}$ ) with rigid cross section without longitudinal stiffness for (a) a line load, (b) a point load, and (c) a train load. Results at $y=0 \mathrm{~m}$ at the soil-mass interface (dashed line) and at the soil's surface at $x=8 \mathrm{~m}$ (solid line).

In the $2 \mathrm{D}$ case, a wall with rigid cross section has two degrees of freedom and thus two modes on the ground stiffness. Apart from a translational mode, a rocking mode is also present. The corresponding 
resonance frequency can be estimated from:

$$
\omega_{0, \theta}=\sqrt{\frac{\hat{K}_{\theta}^{\mathrm{s}}(\omega)}{I_{0}}}
$$

where $\hat{K}_{\theta}^{\mathrm{s}}(\omega)$ represents the rotational dynamic stiffness of the soil under the mass and $I_{0}$ is the mass moment of inertia of the rigid wall around the central axis at $z=0 \mathrm{~m}$ :

$$
I_{0}=\rho\left(\frac{w h^{3}}{3}+\frac{h w^{3}}{12}\right)
$$

The predicted resonance frequency is $21.1 \mathrm{~Hz}$ for the homogeneous halfspace. As the rotational radiation damping in the soil is small, a narrow peak can clearly be seen at $22 \mathrm{~Hz}$ in the insertion loss results at $8 \mathrm{~m}$ (figure 7a). This peak was not observed when the wall is modelled as a distributed line mass without rotational inertia (figure $6 \mathrm{a}$ ).

The mass-spring resonance frequency for vertical translation is now less pronounced in the insertion loss results at the soil-mass interface for all excitation cases. This can be explained by the fact that the radiation damping of the soil for translational motion is larger when the footprint is increased. Moreover, the resonance frequency is shifted to a higher frequency compared to the case of a distributed line mass. This is due to the fact that the dynamic soil stiffness of a rigid foundation with width $1 \mathrm{~m}$ is larger than that for a line mass. The predicted resonance frequency is equal to $41.3 \mathrm{~Hz}$. Above this resonance frequency, the insertion loss at $8 \mathrm{~m}$ increases steadily with increasing frequency.

In contrast to the results for the distributed line mass, a large reduction is also obtained at higher frequencies for positions behind the wall with rigid cross section. Figure 8 compares the wave fields at $90 \mathrm{~Hz}$ with and without wall for the $2 \mathrm{D}$ case. These results show that the rigid masses block the wave field along the interface because the footprint is sufficiently large compared to the Rayleigh wavelength. The vibration reduction at higher frequencies can thus be attributed to the restriction of the ground motion and the hindrance of the propagation of the Rayleigh waves by the wall, as also suggested by Mhanna et al. [25] and Masoumi et al. [26].

\subsection{Model with flexible cross section}

It is now investigated how the behaviour of the wall changes when the flexibility of the cross section is taken into account. Figure 9 shows the insertion loss at $8 \mathrm{~m}$ for a model of a gabion wall that accounts for the flexibility, with and without longitudinal stiffness.

A comparison with the results for the rigid cross section model shows that the behaviour of the masses is again significantly changed when the flexibility of their cross section is taken into account. Above the massspring resonance frequency of approximately $40 \mathrm{~Hz}$, the insertion loss increases strongly up to a frequency of 


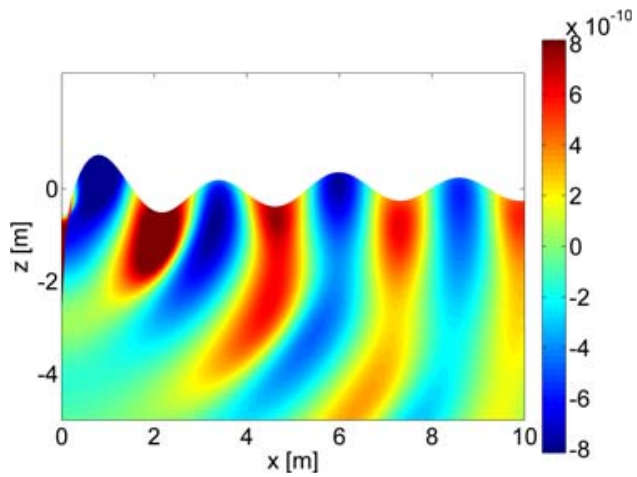

(a)

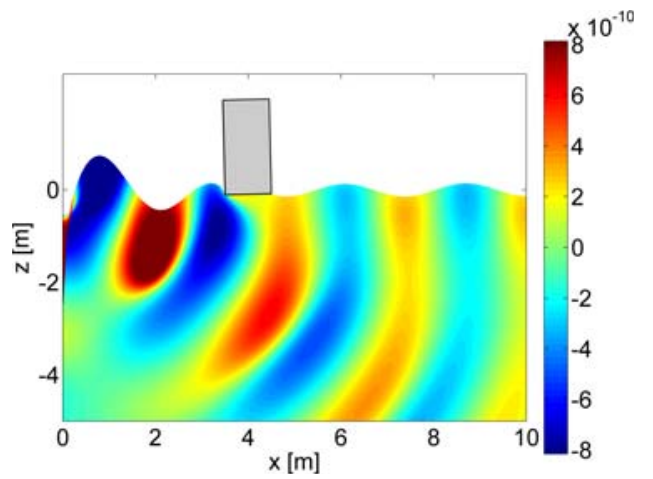

(b)

Figure 8: Real part of the vertical displacement (in $\mathrm{m}$ ) at $90 \mathrm{~Hz}$ for the $2 \mathrm{D}$ case (a) without and (b) with gabion wall (width $1 \mathrm{~m}$, height $2 \mathrm{~m}$ ) with rigid cross section.

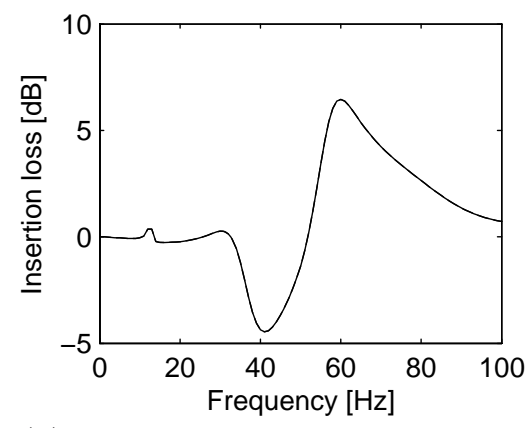

(a)

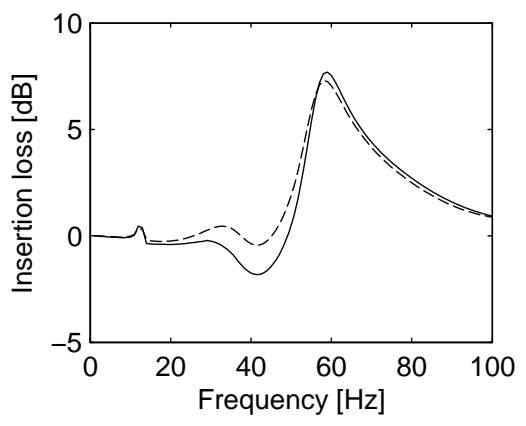

(b)

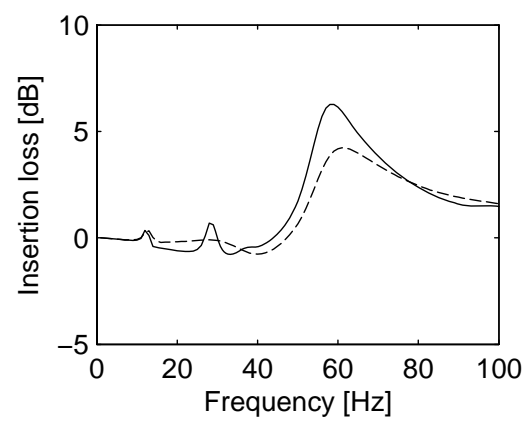

(c)

Figure 9: Vertical insertion loss of a gabion wall (width $1 \mathrm{~m}$, height $2 \mathrm{~m}$ ) with flexible cross section without (solid line) and with (dashed line) longitudinal stiffness for (a) a line load, (b) a point load and (c) a train load. Results at the soil's surface at $y=0 \mathrm{~m}$ and $x=8 \mathrm{~m}$.

$60 \mathrm{~Hz}$ for the masses with flexible cross section. The frequency range with a considerable vibration reduction is broader compared to the case of the distributed line mass (figure 6). The insertion loss values, however, are considerably lower at higher frequencies than for the wall with a rigid cross section (figure 7 ). In this frequency range, the width of the wall is of the same order of magnitude as the Rayleigh wavelength. The interaction between the soil and the wall depends strongly on the flexibility of the wall and its footprint. These results indicate that it is beneficial to make the footprint of the masses as large and stiff as possible to improve the performance at higher frequencies.

The influence of the longitudinal stiffness of the gabion wall on the wave impeding effect is small. It follows directly from equation (6) that the longitudinal stiffness has no effect for the case of a line load, i.e. for $k_{y}=0$ (figure 9a). The influence of the longitudinal stiffness on the insertion loss for a point load is negligible, apart from a small improvement around $40 \mathrm{~Hz}$ (figure $9 \mathrm{~b}$ ). In the frequency range between 40 and $60 \mathrm{~Hz}$, the insertion loss for a train load is 1 to $2 \mathrm{~dB}$ lower when the longitudinal stiffness is taken into account (figure 9c). This indicates that it is better to place the gabions next to each other without any connection. The effect is limited, however, which can be explained by the fact that the stiffness contrast of 
the gabions and the soil is small.

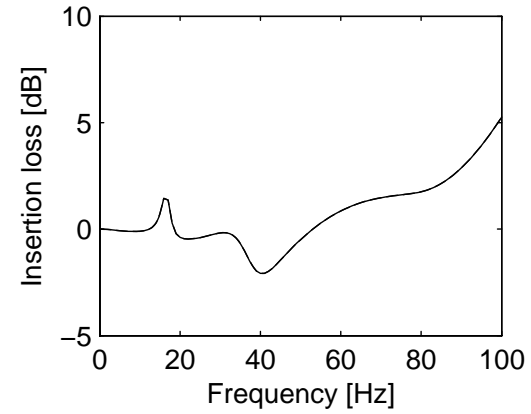

(a)

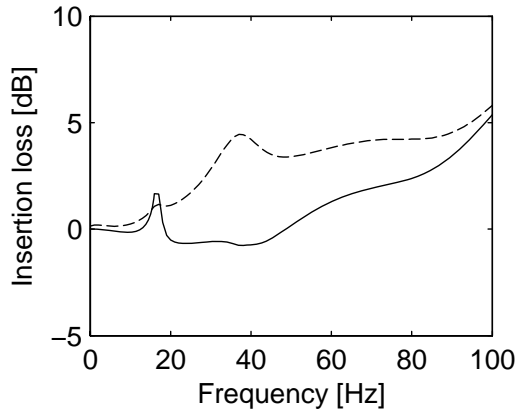

(b)

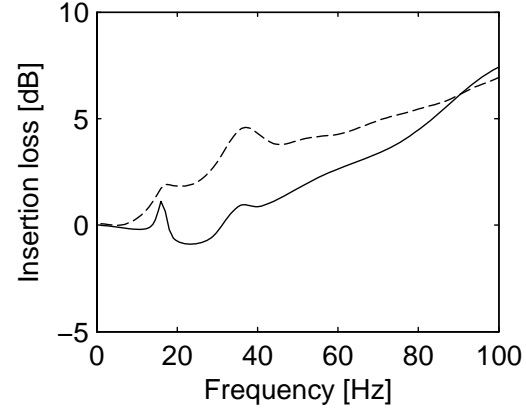

(c)

Figure 10: Vertical insertion loss of a concrete wall (width $1 \mathrm{~m}$, height $2 \mathrm{~m}$ ) with flexible cross section without (solid line) and with (dashed line) longitudinal stiffness for (a) a line load, (b) a point load and (c) a train load. Results at the soil's surface at $y=0 \mathrm{~m}$ and $x=8 \mathrm{~m}$.

The effect of the longitudinal stiffness is much more important when the stiffness contrast between the masses and the soil is large. Figure 10 shows results for a concrete wall with width $1 \mathrm{~m}$ and height $2 \mathrm{~m}$, taking into account the flexibility of the cross section. The concrete wall has a density $\rho=2400 \mathrm{~kg} / \mathrm{m}^{3}$, a shear wave velocity $C_{\mathrm{s}}=2280 \mathrm{~m} / \mathrm{s}$, a Poisson's ratio $\nu=0.20$, and material damping ratios $\beta_{\mathrm{s}}=\beta_{\mathrm{p}}=0.02$. The higher density of the concrete results in a small shift of the natural frequencies compared to the case of the gabion wall. The behaviour of the concrete wall is similar to the one of a wall with rigid cross section. Because it has a stiffness two orders of magnitude larger than the soil, the concrete wall can effectively hinder the propagation of Rayleigh waves at higher frequencies. Again, the longitudinal stiffness has no influence on the results of the $2 \mathrm{D}$ case (figure 10a). The longitudinal stiffness however has a significant effect on the insertion loss for a point and a train load (figures 10b and 10c). The insertion loss is increased by $1-4 \mathrm{~dB}$ already from $9 \mathrm{~Hz}$ on. The concrete wall acts as a stiff wave barrier. The additional wave impeding effect depends on the relationship between the Rayleigh wavelength in the soil and the free bending wavelength in the concrete wall [15]. The wall with longitudinal stiffness reduces transmitted vibrations at frequencies above a critical frequency, where the Rayleigh wavelength in the soil equals the free bending wavelength in the wall. The critical frequency $f_{\mathrm{c}}$ can be calculated from $[15,37]$ :

$$
f_{\mathrm{c}}=\frac{C_{\mathrm{R}}^{2}}{2 \pi} \sqrt{\frac{\rho_{\mathrm{w}} A_{\mathrm{w}}}{E_{\mathrm{w}} I_{\mathrm{w}}}}
$$

where $C_{\mathrm{R}}$ is the Rayleigh wave velocity of the soil, $\rho_{\mathrm{w}}$ the density, $A_{\mathrm{w}}$ the cross sectional area, $E_{\mathrm{w}}$ the Young's modulus and $I_{\mathrm{w}}$ the moment of inertia for bending around the horizontal $x-x$ or vertical $z-z$ axis of the wall. For the concrete wall on a homogeneous halfspace with $C_{\mathrm{R}}=238.6 \mathrm{~m} / \mathrm{s}$, the critical frequencies are equal to $4.4 \mathrm{~Hz}$ and $8.7 \mathrm{~Hz}$ for bending around the horizontal axis and vertical axis, respectively. In the present case, bending around the vertical axis is dominating the wave impeding effect. As a result, 
the concrete wall with longitudinal stiffness is effective above $9 \mathrm{~Hz}$. This wave impeding effect caused by the longitudinal bending stiffness is not seen for the gabion wall, because the stiffness contrast between the gabions and the soil is too low for the wall to act as a stiff wave barrier.

The results for the concrete wall show that results of a $2 \mathrm{D}$ model should be considered with care. While the results for the 2D (line load) and 2.5D (point load and train load) models are similar for the case of the gabion wall on a homogeneous halfspace, this is not generally true for the case of a layered halfspace or a stiff wave barrier.

\section{Parametric study}

\subsection{Introduction}

Table 2 gives an overview of the cases considered in the parametric study for the heavy masses next to the track. Each wall is placed at the sites of Horstwalde, Lincent and Furet (subsection 5.2). These cases are selected to investigate the influence of dynamic soil characteristics and height and width of the masses on the reduction in vibration transmission for the case of a gabion wall. Furthermore, the spatial variation of the insertion loss is discussed.

\begin{tabular}{ccccc}
\hline Case & Material & Width $w[\mathrm{~m}]$ & Height $h[\mathrm{~m}]$ & Position $d[\mathrm{~m}]$ \\
\hline 1 & Gabion wall & 1.0 & 2.0 & 4.0 \\
2 & Gabion wall & $\mathbf{2 . 0}$ & 2.0 & 4.0 \\
3 & Gabion wall & 1.0 & $\mathbf{4 . 0}$ & 4.0 \\
4 & Gabion wall & 1.0 & $\mathbf{6 . 0}$ & 4.0 \\
\hline
\end{tabular}

Table 2: Cases considered in the parametric study of heavy masses next to the track. Parameters deviating from those of the baseline conditions of the reference case (1) are highlighted in bold.

For each case, the vertical insertion loss for a train load excitation is calculated in one-third octave bands. The flexibility of the walls cross section is accounted for in the parametric study. The longitudinal stiffness is taken into account because this gives a conservative prediction for the insertion loss for a train load (section 4.3). A track has been included in all calculations. The physical mechanisms discussed in the previous section remain the same, but the maximum insertion loss values are affected by the presence of the track. The track consists of UIC60 rails, supported by rail pads on monoblock concrete sleepers and a ballast layer with a height of $0.30 \mathrm{~m}$. No sub-ballast, form layer or embankment is included. The parameters of the track are summarized in table 3. Figure 11 shows the finite element discretization of the track. The model of the rails, the rail pads and the sleeper contains four degrees of freedom in the plane of the cross section (vertical translation and rotation of the sleeper and vertical translation of left and right rail) [28]. The rails are modelled as Euler-Bernoulli beams, the rail pads as continuous spring-damper connections and the sleepers as a uniformly distributed mass, rigid in the plane of the cross section. The sleepers are assumed 
not to contribute to the longitudinal stiffness of the track. The ballast is modelled as an elastic continuum by means of eight-node quadrilateral 2.5D finite elements. The discretization of the ballast ensures that there are at least 10 elements per minimal wavelength at $100 \mathrm{~Hz}$. The maximum element size of the ballast is governed by the boundary element size of the soil, as the shear wave velocity of the ballast is larger than the shear wave velocity of the soil. The maximum element size equals $0.24 \mathrm{~m}$ for the Horstwalde site (figure 11). For the other, softer soils considered in the parametric study, a smaller mesh size is used. Similarly, at least 10 finite elements per wavelength are used for the gabion wall, with a minimum of 10 elements over the width and height of the wall in each case.

\begin{tabular}{clrc}
\hline Part & Characteristic & Value & Dimension \\
\hline Rail & bending stiffness $E_{\mathrm{r}} I_{\mathrm{r}}$ & 6.4 & {$\left[\times 10^{6} \mathrm{Nm}^{2}\right]$} \\
& mass per unit length $\rho_{\mathrm{r}} A_{\mathrm{r}}$ & 60 & {$[\mathrm{~kg} / \mathrm{m}]$} \\
& position $l_{1}$ & -0.7175 & {$[\mathrm{~m}]$} \\
& position $l_{2}$ & 0.7175 & {$[\mathrm{~m}]$} \\
\hline Rail pad & stiffness $k_{\mathrm{rp}}$ & 300 & {$\left[\times 10^{6} \mathrm{~N} / \mathrm{m}\right]$} \\
& loss factor $\eta_{\mathrm{rp}}$ & 0.10 & {$[-]$} \\
\hline Sleeper & length $l_{\mathrm{sl}}$ & 2.60 & {$[\mathrm{~m}]$} \\
& width $b_{\mathrm{sl}}$ & 0.25 & {$[\mathrm{~m}]$} \\
& height $h_{\mathrm{sl}}$ & 0.20 & {$[\mathrm{~m}]$} \\
& mass $m_{\mathrm{sl}}$ & 325 & {$[\mathrm{~kg}]$} \\
& sleeper distance $b_{\mathrm{sl}}$ & 0.60 & {$[\mathrm{~m}]$} \\
\hline Ballast & height $h$ & 0.30 & {$[\mathrm{~m}]$} \\
& shear wave velocity $C_{\mathrm{s}}$ & 300 & {$[\mathrm{~m} / \mathrm{s}]$} \\
& Poisson's ratio $\nu$ & $1 / 3$ & {$[-]$} \\
& density $\rho$ & 2000 & {$\left[\mathrm{~kg} / \mathrm{m}^{3}\right]$} \\
& material damping ratio $\beta$ & 0.02 & {$[\mathrm{~m}]$} \\
& upper width $b_{\mathrm{u}}$ & 3.6 & {$[\mathrm{~m}]$} \\
& lower width $b_{1}$ & 5.6 & {$[\mathrm{~m}]$} \\
\hline
\end{tabular}

Table 3: Characteristics of the track.

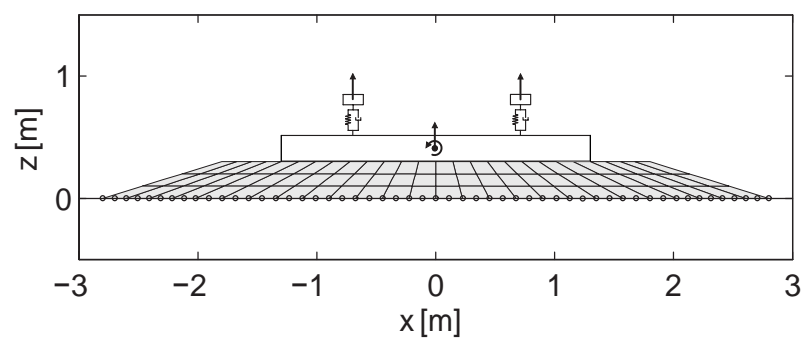

Figure 11: Finite element discretization of the track on the Horstwalde site.

\subsection{Dynamic soil characteristics}

The parametric study focuses on three sites with different soil conditions: Horstwalde, Lincent and Furet [38]. 
The Horstwalde site is a test site of the Federal Institute for Materials Research and Testing (BAM) located $50 \mathrm{~km}$ southeast of Berlin (Germany). Up to a depth of at least $10 \mathrm{~m}$, the soil at the site is a saturated, Märkischer sand with a grain size ranging between fine and coarse sand. The dynamic soil characteristics were identified from a multichannel analysis of surface waves (MASW) test [38]. A value of $245-250 \mathrm{~m} / \mathrm{s}$ was estimated for the shear wave velocity of the soil, while the dilatational wave velocity was estimated to be $1470 \mathrm{~m} / \mathrm{s}$. Cone penetration tests (CPTs) indicated that the soil has a high density. The soil is modelled as a homogeneous halfspace with dynamic soil characteristics given in table 1 .

The site of Lincent (Belgium) is situated next to the high speed line L2 between Brussels and Liège. Conventional soil parameters and a stratification were determined from sample borings and CPT tests. These tests show that the top layer, with a thickness of $1.2 \mathrm{~m}$, is followed by a layer of fine sand which reaches to a depth of $3.2 \mathrm{~m}$. Between depths of 3.2 and $7.5 \mathrm{~m}$, a sequence of hard arenite layers embedded in clay was found [39]. Up to $15 \mathrm{~m}$, the maximum depth of the drilling, a sequence of fine sand and clay layers was found. The groundwater table varied between a minimum depth of $6.0 \mathrm{~m}$ and a maximum depth of $12.2 \mathrm{~m}$, with an average depth of $10.4 \mathrm{~m}$. The dynamic properties of the soil were evaluated by means of five seismic cone penetration tests (SCPT), five spectral analysis of surface waves (SASW) tests and one seismic refraction test [39]. These tests show that the shear wave velocity increases monotonically with depth from approximately $120 \mathrm{~m} / \mathrm{s}$ to $250-300 \mathrm{~m} / \mathrm{s}$. A layered soil model with two softer top layers above a relatively stiff halfspace is used in the simulations. The dynamic soil characteristics for the different soil layers are given in table 4 . The high value for the dilatational wave velocity of the underlying halfspace, determined from the seismic refraction test, is caused by the saturation of the soil.

\begin{tabular}{ccccccc}
\hline Layer & $\begin{array}{c}h \\
{[\mathrm{~m}]}\end{array}$ & $\begin{array}{c}C_{\mathrm{s}} \\
{[\mathrm{m} / \mathrm{s}]}\end{array}$ & $\begin{array}{c}C_{\mathrm{p}} \\
{[\mathrm{m} / \mathrm{s}]}\end{array}$ & $\begin{array}{c}\beta_{\mathrm{s}} \\
{[-]}\end{array}$ & $\begin{array}{c}\beta_{\mathrm{p}} \\
{[-]}\end{array}$ & $\begin{array}{c}\rho \\
{\left[\mathrm{kg} / \mathrm{m}^{3}\right]}\end{array}$ \\
\hline 1 & 1.4 & 128 & 286 & 0.044 & 0.044 & 1800 \\
2 & 2.7 & 176 & 286 & 0.038 & 0.038 & 1800 \\
3 & $\infty$ & 355 & 1667 & 0.037 & 0.037 & 1800 \\
\hline
\end{tabular}

Table 4: Dynamic soil characteristics for the Lincent site.

The site of Furet is located in the southwest of Sweden in the city of Halmstad along the West Coast Line between Gothenburg and Lund. The soil profile consists of a relatively firm layer of sand up to $2-3 \mathrm{~m}$ depth underlain by clayey silt up to a depth of $5-10 \mathrm{~m}$, underlain by silty clay. The silt has a density of $1850 \mathrm{~kg} / \mathrm{m}^{3}$ and the clay a density of $1710 \mathrm{~kg} / \mathrm{m}^{3}$. The shear wave velocity was measured by means of a SCPT and a MASW test [38]. The SCPT test indicates a shear wave velocity of $110 \mathrm{~m} / \mathrm{s}$ between 3 and $14 \mathrm{~m}$, and $150 \mathrm{~m} / \mathrm{s}$ between 15 and $18 \mathrm{~m}$. The MASW test shows a $2 \mathrm{~m}$ thick top layer with a shear wave velocity of $160 \mathrm{~m} / \mathrm{s}$, followed by a $10 \mathrm{~m}$ thick layer with a shear wave velocity of $115 \mathrm{~m} / \mathrm{s}$ and a bottom layer with a shear wave velocity of about $200 \mathrm{~m} / \mathrm{s}$. The presence of the stiffer top layer impedes the determination of the dilatational wave velocity $C_{\mathrm{p}}$ from a seismic refraction test; the values for $C_{\mathrm{p}}$ are estimated from the results 
for $C_{\mathrm{s}}$ assuming a Poisson's ratio of 0.40 . Table 5 provides a summary of the dynamic soil characteristics. While the soil stiffness increases with depth at the site of Lincent, an inverse layering is present at the site of Furet with a stiffer layer on top of a softer layer.

\begin{tabular}{ccccccc}
\hline Layer & $\begin{array}{c}h \\
{[\mathrm{~m}]}\end{array}$ & $\begin{array}{c}C_{\mathrm{s}} \\
{[\mathrm{m} / \mathrm{s}]}\end{array}$ & $\begin{array}{c}C_{\mathrm{p}} \\
{[\mathrm{m} / \mathrm{s}]}\end{array}$ & $\begin{array}{c}\beta_{\mathrm{s}} \\
{[-]}\end{array}$ & $\begin{array}{c}\beta_{\mathrm{p}} \\
{[-]}\end{array}$ & $\begin{array}{c}\rho \\
{\left[\mathrm{kg} / \mathrm{m}^{3}\right]}\end{array}$ \\
\hline 1 & 2 & 154 & 375 & 0.025 & 0.025 & 1800 \\
2 & 10 & 119 & 290 & 0.025 & 0.025 & 1850 \\
3 & $\infty$ & 200 & 490 & 0.025 & 0.025 & 1710 \\
\hline
\end{tabular}

Table 5: Dynamic soil characteristics for the Furet site.

\subsection{Influence of the site conditions}

In this section, the influence of the site characteristics on the effectiveness of a gabion wall with width $1 \mathrm{~m}$ and height $2 \mathrm{~m}$ is investigated. Figure 12 shows the one-third octave band insertion loss values of the gabion wall at the three sites. For the site of Horstwalde, the insertion loss is very small up to a frequency of $30 \mathrm{~Hz}$ (figure 12a). Above the mass-spring resonance frequency, the insertion loss increases up to a maximum value of about $5 \mathrm{~dB}$ at $63 \mathrm{~Hz}$. At higher frequencies, the insertion loss starts to decrease again due to the flexibility of the wall. Due to the softer soil at Furet, the mass-spring resonance frequency is lower and the gabion wall starts to reduce vibrations from $8 \mathrm{~Hz}$ on with a large reduction above $63 \mathrm{~Hz}$ (figure 12c). For the site of Lincent, two maxima are visible in the insertion loss curve (figure 12b). The first maximum occurs in the frequency range $20-30 \mathrm{~Hz}$. A second peak is observed around $50-60 \mathrm{~Hz}$. Below $20 \mathrm{~Hz}$ and above $60 \mathrm{~Hz}$, the reduction is negligible. The variation of the insertion loss values with distance is discussed in the next section.

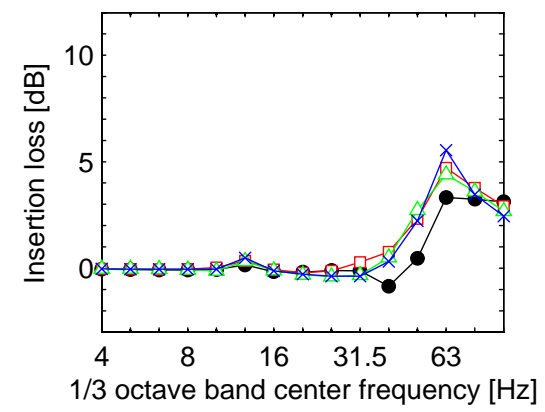

(a)

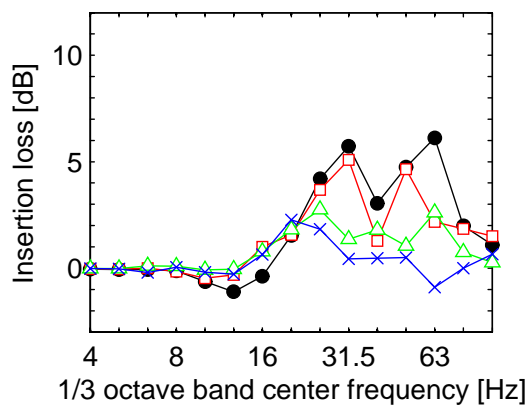

(b)

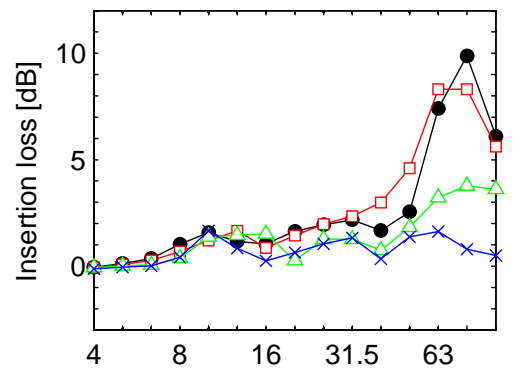

(c)

Figure 12: One-third octave band vertical insertion loss of a gabion wall (width $1 \mathrm{~m}$, height $2 \mathrm{~m}$ ) for a train load at (a) the Horstwalde site, (b) the Lincent site and (c) the Furet site. Results at the soil's surface at $y=0 \mathrm{~m}$ and $x=8 \mathrm{~m}(\bullet), x=16 \mathrm{~m}$ $(\square), x=32 \mathrm{~m}(\triangle)$, and $x=64 \mathrm{~m}(\times)$. 


\subsection{Spatial variation of the insertion loss}

Figure 13 shows the spatial dependence of the insertion loss for a gabion wall with width $1 \mathrm{~m}$ and height $2 \mathrm{~m}$ installed at the Horstwalde site. A harmonic point force is applied to the rails with an excitation frequency of $30 \mathrm{~Hz}, 60 \mathrm{~Hz}$, and $90 \mathrm{~Hz}$. At $30 \mathrm{~Hz}$ (figure 13a), the wave field is not affected by the presence of the gabion wall, leading to an insertion loss of nearly zero almost everywhere in the soil apart from a small zone in close proximity of the wall. At $60 \mathrm{~Hz}$ (figure 13b), the gabion wall can effectively reduce the vibration levels. Waves impinging perpendicular to the wall are reduced most, showing insertion loss values of more than $10 \mathrm{~dB}$ at $y=0 \mathrm{~m}$. The insertion loss is lower for waves impinging at oblique angles. The insertion loss at $90 \mathrm{~Hz}$ is lower than at $60 \mathrm{~Hz}$, but more uniformly distributed along the surface behind the masses (figure 13c). At both $60 \mathrm{~Hz}$ and $90 \mathrm{~Hz}$, no overall increase in vibration levels is observed at the opposite side of the track.

(a)

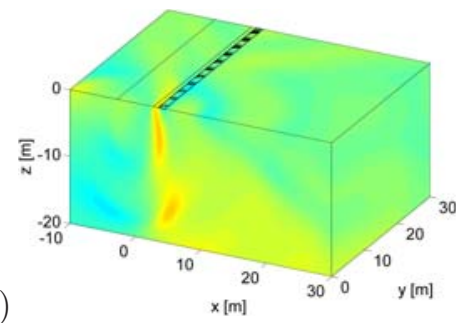

(b)

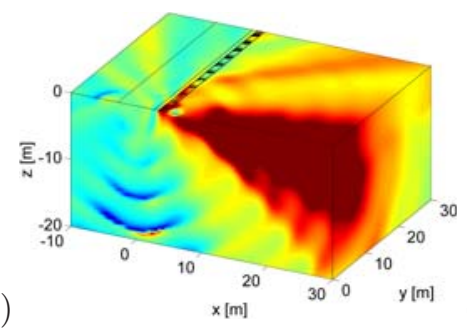

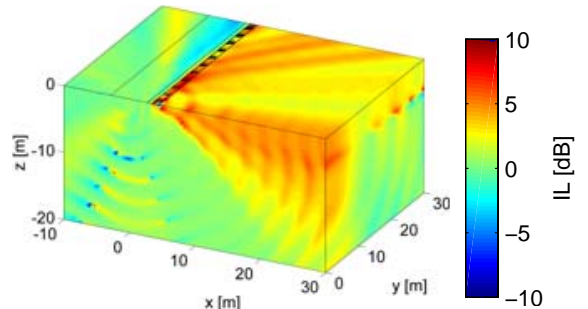

Figure 13: Vertical insertion loss of a gabion wall (width $1 \mathrm{~m}$, height $2 \mathrm{~m}$ ) at the Horstwalde site for a point load applied to both rails at a frequency of (a) $30 \mathrm{~Hz}$, (b) $60 \mathrm{~Hz}$, and (c) $90 \mathrm{~Hz}$.

Figure 14 shows the insertion loss at $30 \mathrm{~Hz}, 60 \mathrm{~Hz}$, and $90 \mathrm{~Hz}$ for the site of Lincent. For all frequencies, there is an irregular pattern of zones with very high and very low insertion loss values at the ground surface behind the wall. For a train passage, these values will be levelled out. The zones where a high reduction is obtained are mainly restricted to the upper soil layers. The gabion wall does not reduce vibration levels in the stiffer halfspace underlying the soft top layers.

(a)

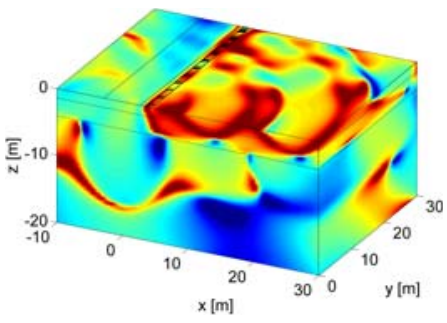

(b)

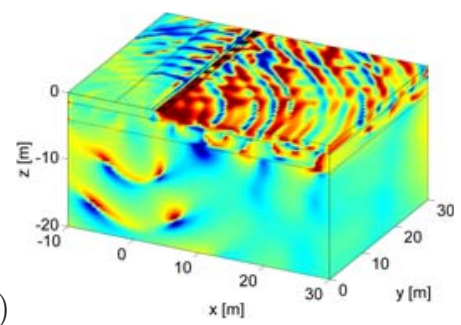

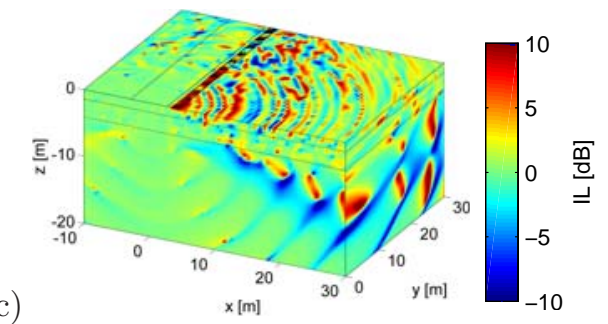

c)

Figure 14: Vertical insertion loss of a gabion wall (width $1 \mathrm{~m}$, height $2 \mathrm{~m}$ ) at the Lincent site for a point load applied to both rails at a frequency of (a) $30 \mathrm{~Hz}$, (b) $60 \mathrm{~Hz}$, and (c) $90 \mathrm{~Hz}$.

Figure 15 shows the insertion loss at $30 \mathrm{~Hz}, 60 \mathrm{~Hz}$, and $90 \mathrm{~Hz}$ for the site of Furet. At $60 \mathrm{~Hz}$ (figure $15 \mathrm{~b}$ ) and $90 \mathrm{~Hz}$ (figure 15c), the spatial variation of the insertion loss is similar to the one at the site of Horstwalde. Very high values of insertion loss are obtained for waves at normal incidence. The insertion 
loss decreases with increasing angle of incidence. At small distances from the wall, the reduction is limited to the upper soil layer. At larger distances from the wall, vibration levels are also reduced in the soft middle layer and in the stiffer halfspace. At $30 \mathrm{~Hz}$ (figure 15a), the insertion loss is small in a large zone behind the wall. Only waves impinging at oblique incidence are effectively mitigated by the wall.

(a)

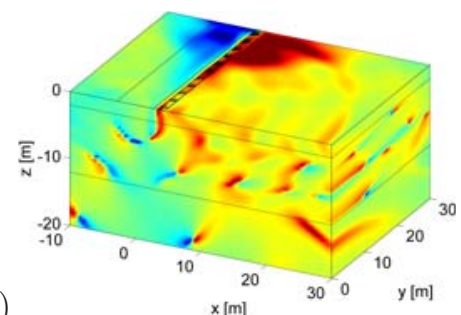

(b)

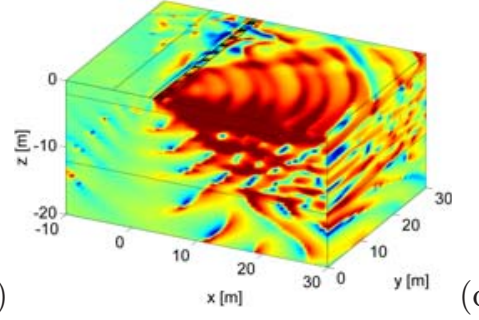

(c)

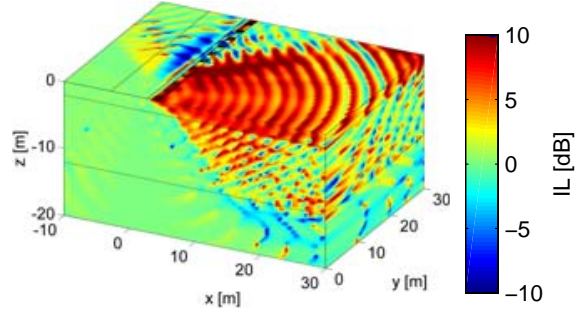

Figure 15: Vertical insertion loss of a gabion wall (width $1 \mathrm{~m}$, height $2 \mathrm{~m}$ ) at the Furet site for a point load applied to both rails at a frequency of (a) $30 \mathrm{~Hz}$, (b) $60 \mathrm{~Hz}$, and (c) $90 \mathrm{~Hz}$.

The influence of the distance to the wall on the one-third octave band insertion loss values at the three sites is shown in figure 12. The response at the soil's surface at distances of $8 \mathrm{~m}, 16 \mathrm{~m}, 32 \mathrm{~m}$, and $64 \mathrm{~m}$ from the centre of the track is considered. For the homogeneous halfspace of Horstwalde, the insertion loss is almost independent of the distance (figure 12a). At $8 \mathrm{~m}$, the reduction is smaller between $40 \mathrm{~Hz}$ and $63 \mathrm{~Hz}$. Around the mass-spring resonance frequency of $40 \mathrm{~Hz}$, there is even an increase in vibration levels. At Lincent, the insertion loss decreases strongly with increasing distance behind the wall (figure $12 \mathrm{~b}$ ). At $8 \mathrm{~m}$, a dip in insertion loss is observed around the mass-spring resonance frequency of $12 \mathrm{~Hz}$. The effectiveness of the gabion wall decreases for larger distances behind the wall for the site of Furet as well, especially at higher frequencies (figure 12c).

Figure 16 shows the effectiveness at different depths at the three sites. The vertical insertion loss at a distance of $8 \mathrm{~m}$ from the track is shown for four depths: $0 \mathrm{~m}, 3 \mathrm{~m}, 6 \mathrm{~m}$, and $9 \mathrm{~m}$. As can be expected, the influence of depth is small at low frequencies and becomes larger at high frequencies for all three sites. For the site of Horstwalde, the insertion loss decreases gradually with increasing depth above $50 \mathrm{~Hz}$ (figure 16a). At larger distances from the track, the reduction is significant up to a depth of $9 \mathrm{~m}$ (figure 13). The same trends are visible at the site of Furet (figure 16c). For the site of Lincent, the depth of $3 \mathrm{~m}$ is located in the middle of the second layer, while the depths of $6 \mathrm{~m}$ and $9 \mathrm{~m}$ are located in the stiffer halfspace (table 4). There is no reduction in vibrations at frequencies above $20 \mathrm{~Hz}$ in this underlying halfspace (figure $16 \mathrm{~b}$ ).

\subsection{Influence of the height of the masses}

In this section, the influence of the height of the masses is investigated. Three heights are considered for a gabion wall: $2 \mathrm{~m}, 4 \mathrm{~m}$, and $6 \mathrm{~m}$. Figure 17 shows the corresponding insertion loss values at $8 \mathrm{~m}$ from the track for the three sites. For the site of Horstwalde, increasing the height of the wall improves the effectiveness at low frequencies (figure 17a). The mass-spring resonance frequency which determines the onset of vibration 


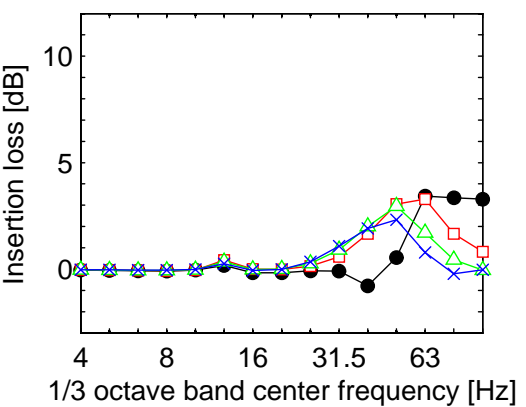

(a)

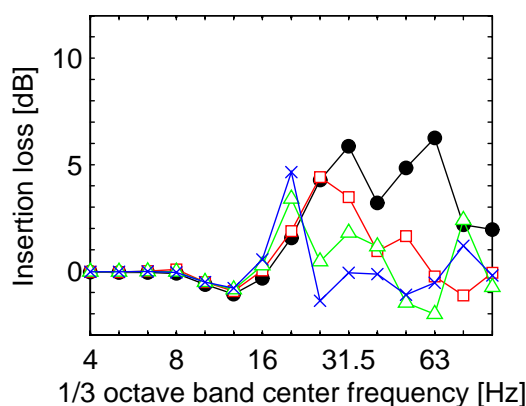

(b)

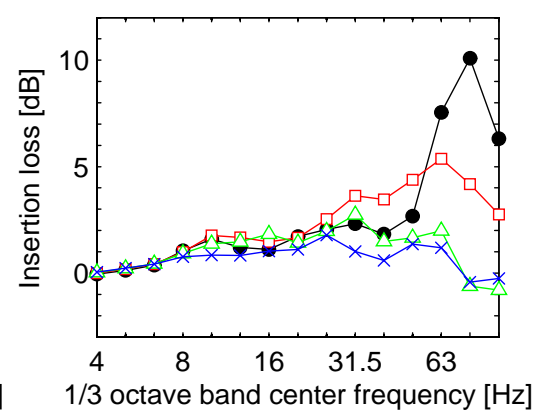

(c)

Figure 16: One-third octave band vertical insertion loss of a gabion wall (width $1 \mathrm{~m}$, height $2 \mathrm{~m}$ ) for a train load at (a) the Horstwalde site, (b) the Lincent site and (c) the Furet site. Results at $x=8 \mathrm{~m}$ and $y=0 \mathrm{~m}$ at a depth of $0 \mathrm{~m}(\bullet), 3 \mathrm{~m}(\square), 6 \mathrm{~m}$ $(\triangle)$, and $9 \mathrm{~m}(\times)$.

reduction is decreased by increasing the mass of the wall. For the $2 \mathrm{~m}$ high wall, the insertion loss increases from the one-third octave band of $40 \mathrm{~Hz}$ onwards. For the $4 \mathrm{~m}$ and $6 \mathrm{~m}$ high walls, positive insertion loss values are found from the one-third octave bands of $20 \mathrm{~Hz}$ and $16 \mathrm{~Hz}$ onwards, respectively. The same trends are visible in the results for the sites of Lincent (figure 17b) and Furet (figure 17c). Increasing the height of the wall enhances the effectiveness at low frequencies. At higher frequencies (above $20 \mathrm{~Hz}$ for the site of Lincent and above $30 \mathrm{~Hz}$ for the site of Furet), the influence of the height of the wall is limited.

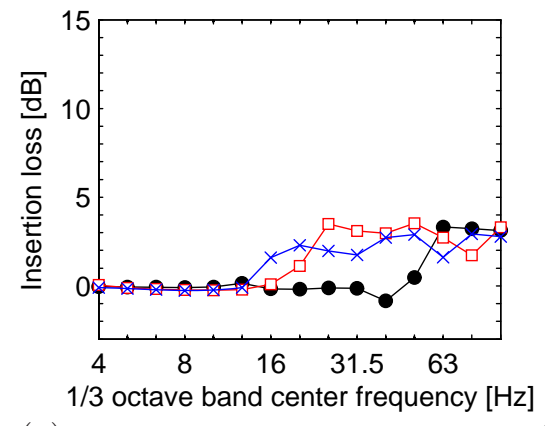

(a)

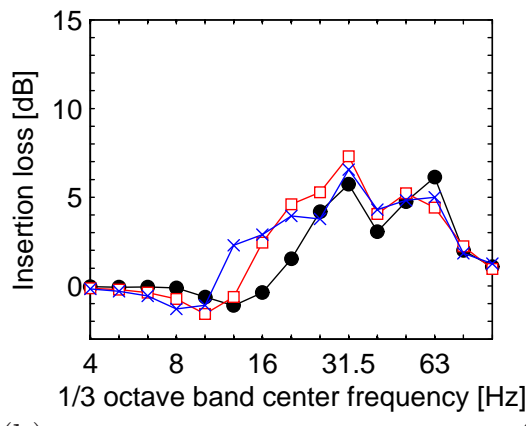

(b)

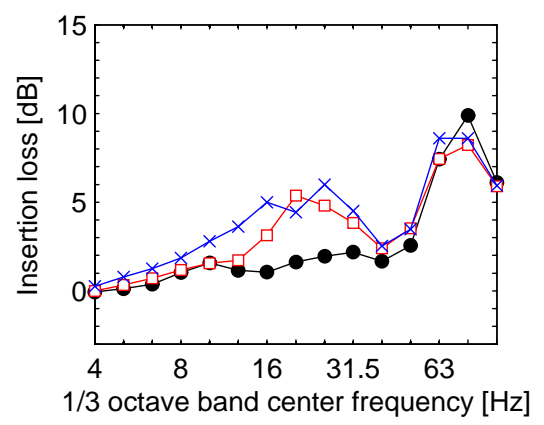

(c)

Figure 17: One-third octave band vertical insertion loss of a gabion wall (width $1 \mathrm{~m}$ ) with a height of $2 \mathrm{~m}(\bullet), 4 \mathrm{~m}(\square)$, and $6 \mathrm{~m}(\times)$ for a train load at (a) the Horstwalde site, (b) the Lincent site, and (c) the Furet site. Results at the soil's surface at $y=0 \mathrm{~m}$ and $x=8 \mathrm{~m}$.

\subsection{Influence of the width of the masses}

Figure 18 shows the influence of the width of a gabion wall with a height of $2 \mathrm{~m}$ at the three sites. For all three sites, doubling the width of the wall from $1 \mathrm{~m}$ to $2 \mathrm{~m}$ increases the effectiveness in a broad frequency range. The higher mass results in a lower mass-spring resonance frequency and, therefore, an improved performance at low frequencies. Furthermore, Rayleigh waves are hindered more effectively due to the larger footprint of the wall. As a result, the insertion loss is also improved at higher frequencies. 


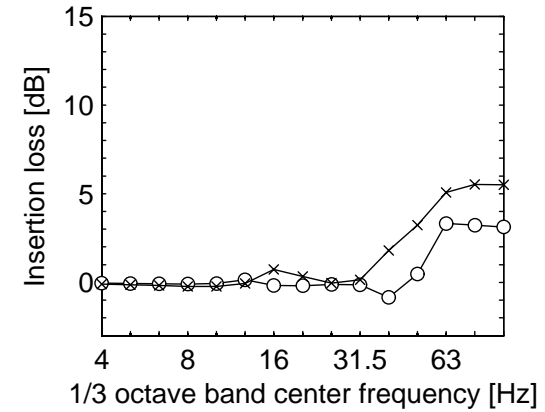

(a)

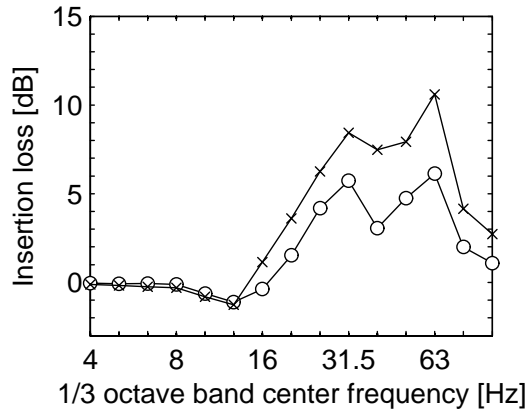

(b)

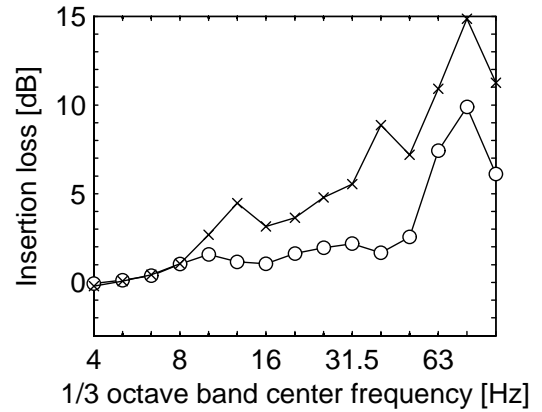

(c)

Figure 18: One-third octave band vertical insertion loss of a gabion wall (height $2 \mathrm{~m}$ ) with a width of $1 \mathrm{~m}(\mathrm{o})$ and $2 \mathrm{~m}(\times)$ for a train load at (a) the Horstwalde site, (b) the Lincent site and (c) the Furet site. Results at the soil's surface at $y=0 \mathrm{~m}$ and $x=8 \mathrm{~m}$.

Finally, it is interesting to compare the effectiveness of the gabion wall with width $2 \mathrm{~m}$ and height $2 \mathrm{~m}$ (figure 18) with the one of a gabion wall with width $1 \mathrm{~m}$ and height $4 \mathrm{~m}$ (figure 17), i.e. with the same overall mass. The insertion loss for the wider wall is larger at higher frequencies (above $40 \mathrm{~Hz}$ for the Horstwalde site and $25 \mathrm{~Hz}$ for the Lincent site). The larger width enhances the hindrance of surface waves. At lower frequencies, the higher wall performs better at the sites of Horstwalde and Lincent. This indicates that, depending on the frequency range of interest, it may be better to increase either the width or the height of the wall. For the site of Furet, the insertion loss for the wider wall is higher in almost the entire frequency range considered.

In addition to the cases of table 2 , the influence of placing a concrete foundation under the gabion wall and the influence of the position of the gabion wall next to the track have been investigated as well. Doubling the distance of the gabion wall from the track from $4 \mathrm{~m}$ to $8 \mathrm{~m}$ slightly decreases the efficiency of the gabion wall, but the effect is limited. Similarly, adding a concrete foundation does not improve the insertion loss significantly. Because the effects are small, these cases are not shown for the sake of brevity.

\section{Conclusions}

In this paper, a continuous row of heavy masses forming a wall next to the track is studied as a mitigation measure for railway induced ground vibration. The effectiveness of the wall is determined by means of 2.5D simulations. The physical mechanisms responsible for the wave impeding effect are discussed, showing that the behaviour of the walls is much more complex than that of a simple line mass. The effects of flexibility and finite dimensions of the walls have to be accounted for in the assessment of the vibration reduction, which makes numerical simulations indispensable.

The masses can lead to a reduction in vibration levels above a mass-spring resonance frequency which is determined by the vertical dynamic stiffness of the soil and the mass of the wall. Therefore, masses will be 
more effective at sites with a soft soil. Increasing the mass by increasing the height of the wall also reduces the mass-spring resonance frequency and therefore improves the performance at lower frequencies. At higher frequencies, transmitted surface vibrations are reduced due to the fact that the propagation of surface waves is hindered, provided the stiffness contrast between soil and wall is large enough. Increasing the width can therefore improve the performance at higher frequencies. For a homogeneous halfspace, the insertion loss for a train passage is almost independent of the distance behind the wall. For a layered halfspace with a soft upper layer, the insertion loss typically decreases with increasing distance behind the wall and increasing depth. The paper mainly focusses on the application of a gabion wall, also used as noise barrier, as a feasible mitigation measure for ground-borne vibration. The effectiveness of a gabion wall is also compared with that of a continuous concrete wall. A higher insertion loss is found for the concrete wall at low frequencies. This can mainly be attributed to the additional longitudinal bending stiffness of the concrete wall.

\section{Acknowledgements}

The first and second author are postdoctoral fellows of the Research Foundation Flanders (FWO). The results have been obtained within the frame of the EU FP7 project RIVAS (Railway Induced Vibration Abatement Solutions) [10] under grant agreement No. 265754. The financial support is gratefully acknowledged.

\section{References}

[1] C. Jones, Use of numerical models to determine the effectiveness of anti-vibration systems for railways, Proceedings of the Institution of Civil Engineers-Transport 105 (1) (1994) 43-51.

[2] A. Kaynia, C. Madshus, P. Zackrisson, Ground vibration from high speed trains: prediction and countermeasure, Journal of Geotechnical and Geoenvironmental Engineering, Proceedings of the ASCE 126 (6) (2000) 531-537.

[3] B. Hemsworth, Reducing groundborne vibrations: state of the art study, Journal of Sound and Vibration 231 (3) (2000) 703-709.

[4] R. Hildebrand, Effect of soil stabilization on audible band railway ground vibration, Soil Dynamics and Earthquake Engineering 24 (2004) 411-424.

[5] H. Loy, Mitigating vibration using under-sleeper pads, Railway Gazette International 168 (4) (2012) 40-43.

[6] R. Müller, Mitigation measures for open lines against vibration and ground-borne noise: a Swiss overview, in: B. SchulteWerning, D. Thompson, P.-E. Gautier, C. Hanson, B. Hemsworth, J. Nelson, T. Maeda, P. de Vos (Eds.), Noise and Vibration Mitigation for Rail Transportation Systems, Vol. 99 of Notes on Numerical Fluid Mechanics and Multidisciplinary Design, Springer Berlin / Heidelberg, 2008, pp. 264-270.

[7] P. Costa, R. Calçada, A. Cardoso, Ballast mats for the reduction of railway traffic vibrations. Numerical study, Soil Dynamics and Earthquake Engineering 42 (2012) 137-150.

[8] J. Nelson, Recent developments in ground-borne noise and vibration control, Journal of Sound and Vibration 193 (1) (1996) 367-376.

[9] J. Talbot, H. Hunt, A generic model for evaluating the performance of base-isolated buildings, Journal of Low Frequency Noise, Vibration and Active Control 22 (3) (2003) 149-160. 
[10] http://www.rivas-project.eu (2011).

[11] A. Karlström, A. Boström, Efficiency of trenches along railways for trains moving at sub- or supersonic speeds, Soil Dynamics and Earthquake Engineering 27 (2007) 625-641.

[12] R. Woods, Screening of surface waves in soils, Journal of the Soil Mechanics and Foundation Division, Proceedings of the ASCE 94 (SM4) (1968) 951-979.

[13] S. Kattis, D. Polyzos, D. Beskos, Vibration isolation by a row of piles using a 3-D frequency domain BEM, International Journal for Numerical Methods in Engineering 46 (1999) 713-728.

[14] K. Massarsch, Vibration isolation using gas-filled cushions, in: Proceedings of the Geo-Frontiers 2005 Congress, American Society of Civil Engineers, Austin, Texas, 2005.

[15] P. Coulier, S. François, G. Degrande, G. Lombaert, Subgrade stiffening next to the track as a wave impeding barrier for railway induced vibrations, Soil Dynamics and Earthquake Engineering 48 (2013) 119-131.

[16] L. Andersen, S. Nielsen, Reduction of ground vibration by means of barriers or soil improvement along a railway track, Soil Dynamics and Earthquake Engineering 25 (2005) 701-716.

[17] A. Peplow, A. Kaynia, Prediction and validation of traffic vibration reduction due to cement column stabilization, Soil Dynamics and Earthquake Engineering 27 (2007) 793-802.

[18] H. Hung, Y. Yang, D. Chang, Wave barriers for reduction of train-induced vibrations in soils, Journal of Geotechnical Engineering, Proceedings of the ASCE 130 (12) (2004) 1283-1291.

[19] X. Sheng, C. Jones, D. Thompson, Prediction of ground vibration from trains using the wavenumber finite and boundary element methods, Journal of Sound and Vibration 293 (2006) 575-586.

[20] V. Krylov, Control of traffic-induced ground vibrations by placing heavy masses on the ground surface, Journal of Low Frequency Noise, Vibration and Active Control 26 (4) (2007) 311-320.

[21] E. Garova, A. Maradudin, A. Mayer, Interaction of Rayleigh waves with randomly distributed oscillators on the surface, Physical Review B 59 (20) (1999) 13291-13296.

[22] D. Clouteau, D. Aubry, Modification of the ground motion in dense urban areas, Journal of Computational Acoustics 9 (4) (2001) 1659-1675.

[23] G. Lombaert, D. Clouteau, The resonant multiple wave scattering in the seismic response of a city, Waves in Random and Complex Media 16 (3) (2006) 205-230.

[24] G. Lombaert, D. Clouteau, Elastodynamic wave scattering by finite-sized resonant scatterers at the surface of a horizontally layered halfspace, Journal of the Acoustical Society of America 125 (4) (2009) 2041-2052.

[25] M. Mhanna, I. Shahrour, M. Sadek, P. Dunez, Efficiency of heavy mass technology in traffic vibration reduction: Experimental and numerical investigation, Computers and Geotechnics 55 (2014) 141-149.

[26] H. Masoumi, A. Van Leuven, S. Urbaniak, Mitigation of train induced vibrations by wave impeding blocks: numerical prediction and experimental validation, in: A. Cunha, E. Caetano, P. Ribeiro, G. Müller (Eds.), Proceedings of the 9th International Conference on Structural Dynamics, Eurodyn 2014, Porto, Portugal, 2014, pp. 863-870.

[27] F. Koussa, J. Defrance, P. Jean, P. Blanc-Benon, Acoustic performance of gabions noise barriers: Numerical and experimental approaches, Applied Acoustics 74 (1) (2013) 189-197.

[28] G. Lombaert, G. Degrande, J. Kogut, S. François, The experimental validation of a numerical model for the prediction of railway induced vibrations, Journal of Sound and Vibration 297 (3-5) (2006) 512-535.

[29] D. Thompson, Railway noise and vibration: mechanisms, modelling, and means of control, Elsevier, Oxford, 2009.

[30] H. Verbraken, G. Lombaert, G. Degrande, Verification of an empirical prediction method for railway induced vibrations by means of numerical simulations, Journal of Sound and Vibration 330 (8) (2011) 1692-1703.

[31] S. François, M. Schevenels, G. Lombaert, P. Galvín, G. Degrande, A 2.5D coupled FE-BE methodology for the dynamic interaction between longitudinally invariant structures and a layered halfspace, Computer Methods in Applied Mechanics 
and Engineering 199 (23-24) (2010) 1536-1548.

[32] C.-M. Nilsson, C. Jones, Theory manual for WANDS 2.1, ISVR Technical Memorandum 975, University of Southampton (2007).

[33] E. Kausel, J. Roësset, Stiffness matrices for layered soils, Bulletin of the Seismological Society of America 71 (6) (1981) $1743-1761$.

[34] M. Schevenels, S. François, G. Degrande, EDT: An ElastoDynamics Toolbox for MATLAB, Computers \& Geosciences 35 (8) (2009) 1752-1754.

[35] X. Sheng, C. Jones, D. Thompson, Modelling ground vibrations from railways using wavenumber finite- and boundaryelement methods, Proceedings of the Royal Society A - Mathematical, Physical and Engineering Sciences 461 (2005) 2043-2070.

[36] A. Mirza, A. Frid, J. Nielsen, C. Jones, Ground vibrations induced by railway traffic - the influence of vehicle parameters, in: B. Schulte-Werning, D. Thompson, P.-E. Gautier, C. Hanson, B. Hemsworth, J. Nelson, T. Maeda, P. de Vos (Eds.), Proceedings of the 10th International Workshop on Railway Noise IWRN10, Vol. 118 of Notes on Numerical Fluid Mechanics and Multidisciplinary Design, Springer, Nagahama, Japan, 2012, pp. 259-266.

[37] C. Hopkins, Sound insulation, Elsevier Ltd., Oxford, 2007.

[38] P. Coulier, G. Degrande, A. Dijckmans, J. Houbrechts, G. Lombaert, W. Rücker, L. Auersch, M. Plaza, V. Cuellar, D. Thompson, A. Ekblad, A. Smekal, Scope of the parametric study on mitigation measures on the transmission path, RIVAS project SCP0-GA-2010-265754, Deliverable D4.1, Report to the EC (October 2011).

[39] L. Karl, Dynamic soil properties out of SCPT and bender element tests with emphasis on material damping, Ph.D. thesis, Universiteit Gent (2005). 